\title{
A Radiographic Study of Patients Treated with the Reinforced Banded Herbst Appliance
}

Travis Tomblyn

Follow this and additional works at: https://researchrepository.wvu.edu/etd

\section{Recommended Citation}

Tomblyn, Travis, "A Radiographic Study of Patients Treated with the Reinforced Banded Herbst Appliance" (2015). Graduate Theses, Dissertations, and Problem Reports. 6817.

https://researchrepository.wvu.edu/etd/6817

This Thesis is protected by copyright and/or related rights. It has been brought to you by the The Research Repository @ WVU with permission from the rights-holder(s). You are free to use this Thesis in any way that is permitted by the copyright and related rights legislation that applies to your use. For other uses you must obtain permission from the rights-holder(s) directly, unless additional rights are indicated by a Creative Commons license in the record and/ or on the work itself. This Thesis has been accepted for inclusion in WVU Graduate Theses, Dissertations, and Problem Reports collection by an authorized administrator of The Research Repository @ WVU. For more information, please contact researchrepository@mail.wvu.edu. 


\title{
A Radiographic Study of Patients Treated with the Reinforced Banded Herbst Appliance
}

\author{
Travis Tomblyn, D.D.S.
}

\author{
A THESIS \\ Submitted to: \\ The School of Dentistry \\ at West Virginia University \\ in partial fulfillment of the requirements \\ for the degree of
}

Masters of Science

In

Orthodontics

Committee members:

Peter Ngan, D.M.D., Chair

Chris Martin, D.D.S., M.S.

Timothy Tremont D.M.D., M.S.

Department of Orthodontics

Morgantown, West Virginia

2015 


\title{
ABSTRACT
}

\section{A Radiographic Study of Patients Treated with the Reinforced Banded Herbst Appliance}

\author{
Travis G. Tomblyn D.D.S., Peter Ngan, D.M.D., Chris Martin, D.D.S., M.S., \\ Timothy Tremont D.M.D., M.S., Erdogan Gunel, PhD.
}

Objectives: Orthopedic functional appliances have been shown to be effective in correcting Class II malocclusions with mandibular deficiency. However, most of the studies reported in the literature could not substantiate the effect of the appliance on mandibular growth because the appliance was worn for a short time and most of the studies were short term. In addition, there is also report on the breakage of the appliance with the use of the banded Herbst design. The objective of this study was to investigate the skeletal and dental changes of patients treated with the reinforced banded Herbst appliance during Herbst treatment and after completion of fixed appliance treatment. The results of this research should provide additional information on mode of action and the length of treatment when using the Herbst appliance. Methods: Thirty patients with Class II division 1 malocclusion (mean age $=12.34$ years) treated by one of the investigator (M.R.) with Herbst followed by fixed appliance were compared to a matched control sample obtained from the Bolton-Brush study. Cephalometric radiographs were taken before treatment (T1), at the completion of Herbst treatment (T2), and following the removal of all fixed appliances (T3). Data was analyzed using a combination of ANOVA and Tukey-Kramer Test. Results: Treatment with the Herbst appliance (T2-T1) for an average of 1.5 years after growth is subtracted ( $\mathrm{t} 2-\mathrm{t} 1)$ resulted in a backward movement of the maxilla by $1.2 \mathrm{~mm}$. The mandible moved forward $1.3 \mathrm{~mm}$. The maxillary molars moved backward $4 \mathrm{~mm}$ and the maxillary incisors moved backward $4 \mathrm{~mm}$. The mandibular molars moved forward $3.5 \mathrm{~mm}$ and the lower incisors moved forward $3.2 \mathrm{~mm}$. The vertical changes were the maxilla moved downward $1.2 \mathrm{~mm}$. The upper molars intruded $1 \mathrm{~mm}$. The lower molar intruded $1 \mathrm{~mm}$ and the lower incisors intruded 1.1 $\mathrm{mm}$. The overbite decreased by $3.3 \mathrm{~mm}$. The angular changes were SNB increased $3.6^{\circ}$. The SNA and ANB decreased $1^{\circ}$ and $4.5^{\circ}$. The occlusal plane increased by about $5^{\circ}$. The upper incisor retracted $5.5^{\circ}$ and the lower incisor proclined $8.6^{\circ}$. The Wits decreased by 4.2 . The change in overjet was $-7.2 \mathrm{~mm}$. The skeletal contribution was $-2.5 \mathrm{~mm}$ and the dental contribution was $-4.7 \mathrm{~mm}$. The change in molar relationship was $-7.5 \mathrm{~mm}$. The skeletal contribution was $-2.5 \mathrm{~mm}$ and the dental contribution was $-5 \mathrm{~mm}$. The maxilla, maxillary molars, and maxillary incisors moved backwards. The mandible, mandibular molars, and mandibular incisors moved forward. The total treatment effect of the Herbst appliance and phase II treatment (T3-T1) after growth is subtracted (t3-t1) resulted in a backward movement of the maxilla by .4 $\mathrm{mm}$. The mandible moved forward $.9 \mathrm{~mm}$. The maxillary molars moved backward $2.3 \mathrm{~mm}$ and the maxillary incisors moved backward $1.5 \mathrm{~mm}$. The mandibular molars moved forward $2.7 \mathrm{~mm}$ and the lower incisors moved forward $2.9 \mathrm{~mm}$. The vertical changes were the maxilla moved 
downward $1.2 \mathrm{~mm}$. The upper molars extruded $.3 \mathrm{~mm}$ and the lower molar extruded $.8 \mathrm{~mm}$. The overbite decreased by $4.2 \mathrm{~mm}$. The angular changes were SNB increased $2.6^{\circ}$. The SNA and ANB decreased $.2^{\circ}$ and $3.3^{\circ}$. The occlusal plane increased by about $1.2^{\circ}$. The upper incisor retracted $5^{\circ}$ and the lower incisor proclined $4.5^{\circ}$. The Wits decreased by 3.2. The change in overjet was $-4.4 \mathrm{~mm}$. The skeletal contribution was $-1.3 \mathrm{~mm}$ and the dental contribution was -3.1 $\mathrm{mm}$. The change in molar relationship was $-5 \mathrm{~mm}$. The skeletal contribution was $-1.3 \mathrm{~mm}$ and the dental contribution was $-3.7 \mathrm{~mm}$. The maxilla, maxillary molars, and maxillary incisors moved backwards. The mandible, mandibular molars, and mandibular incisors moved forward. Conclusions: The Herbst appliance when used for an average of 1.5 years was effective in correcting class II dental and skeletal malocclusions. The Herbst appliance when used for a longer period of time seems to allow for more over correction and less relapse. 


\section{DEDICATION}

To my beautiful wife, Jennifer Lynn Tomblyn, who is my best friend and the love of my life. This has been an incredible journey and I am so excited to start the next chapter of our lives together.

To my parents, Gary and RoseMary Tomblyn, who have been with me and supported me from day one. Thank you for always being there.

To my siblings, Paula Ball and Sarah Kesling, I want to thank you for serving as role models, I couldn't ask for better sisters.

To my in-laws, Bill and Suzanne Mitchel, who have taken me in and treated me like one of their own. Thank you for everything.

To God, who has provided me with the strength, courage, and perseverance to succeed in life and for surrounding me with amazing friends and family. 


\section{ACKNOWLEDGEMENTS}

Special thanks are extended to the following individuals.

Dr. Peter Ngan, for being my research committee chairman.

Dr. Chris Martin, for being a member of my thesis committee, for your everyday advice in the clinic, and full-time commitment to this program.

Dr. Timothy Tremont, for being a member of my thesis committee, for his teaching of the six elements and serving as the foundation to our learning at this program.

Dr. Mike Rogers, for the use of his office and records, for his enthusiasm for the Herbst appliance and his desire to improve the design in order to provide the highest quality of treatment to his patients.

Dr. Lee Andrews, for the use of his office, records, and hospitality while collecting data.

Dr. Erdogan Gunel, for his statistical assistance and willingness to work with us any time he was needed.

Drs. Mike Hazey, Scott Little, Daniel Foley, Edward McFarland, Thomas Jarrett, Kerry Kirsch, Lou Wright, and Glen Boyles, for the invaluable lessons in the classroom and the clinic. Thank you for taking time away from your busy practices and spending it with us instead of the golf course!

Leona and Karen, for your friendship and assistance in the clinic. I have really enjoyed working with you both.

Carrie, for all your hard work in keeping everyone coordinated and on schedule.

Dr. Nicholas Maddux, my co-resident, for his constant support and being the best $3^{\text {rd }}$ wheel EVER! We have become great friends and I wish you and Kristen the best.

Chad, Doyoung, Alice, Nicole, Deepa, and Lance, my fellow residents, for their friendship and guidance through the program. Thanks for everything.

Tim, Jason, Martin, Marina, Dobin, Uyen, and Amer, my fellow residents, for the good times, friendship, and support throughout the program. 


\section{Contents}



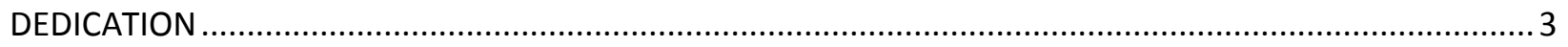

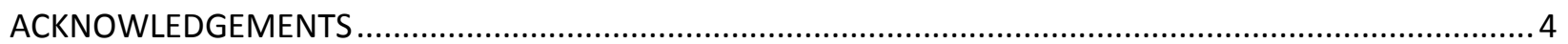

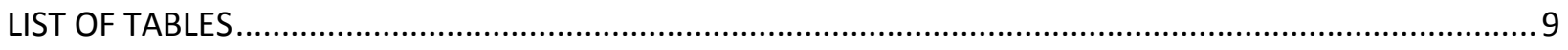



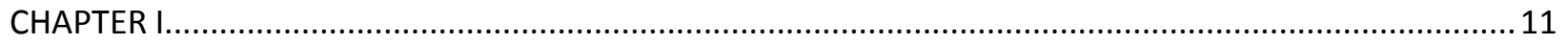

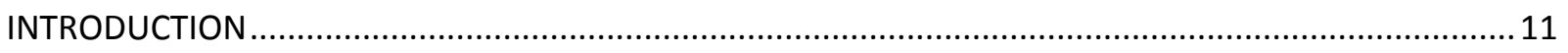

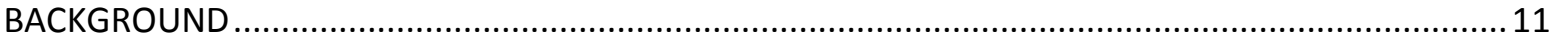

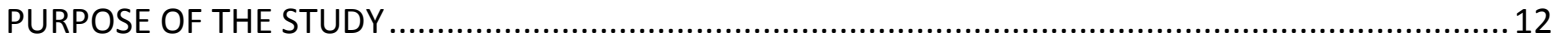

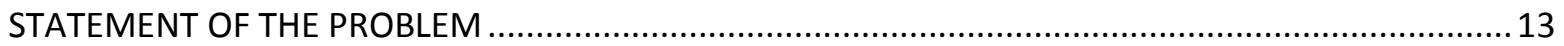

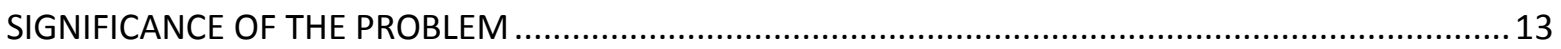

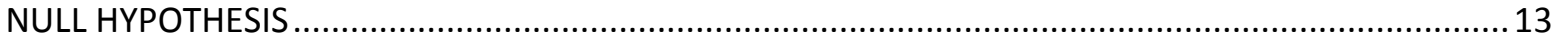

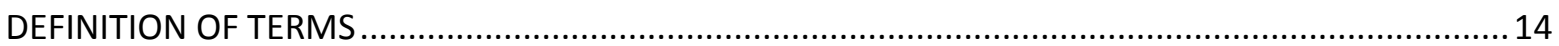





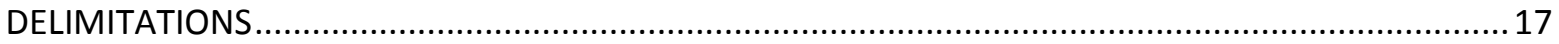

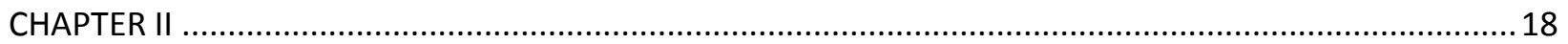

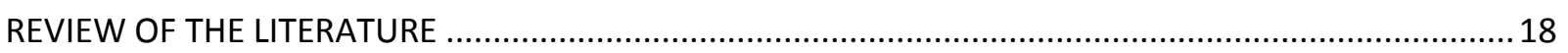

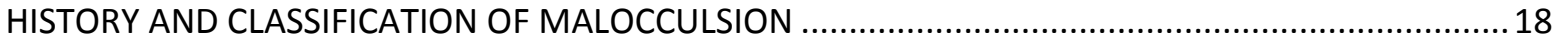

ETIOLOGY OF MALOCCLUSION AND THE NEED FOR ORTHODONTIC THERAPY .............................. 19

ETIOLOGY AND PRESENTATION OF CLASS II MALOCCLUSION......................................................... 19

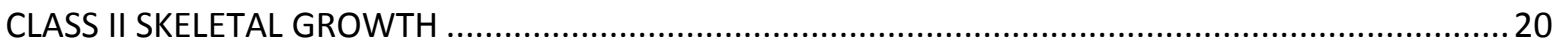

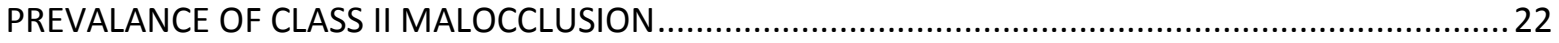

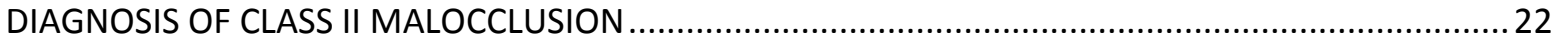

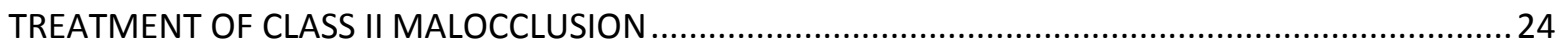

FUNCTIONAL APPLIANCE THERAPY TO TREAT CLASS II MALOCCLUSION ....................................... 25

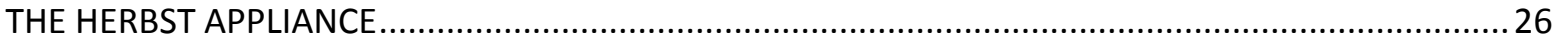

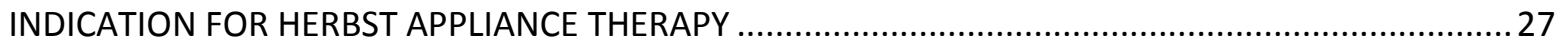

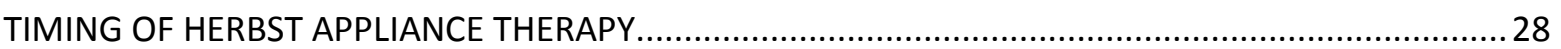

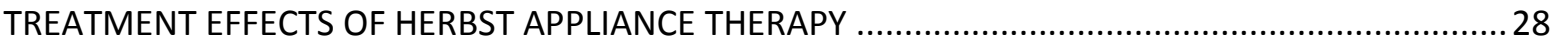

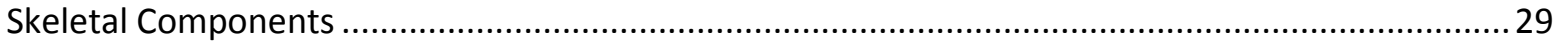




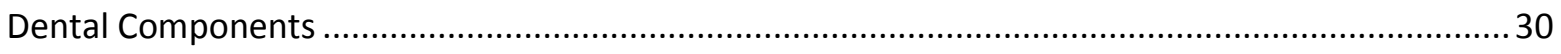

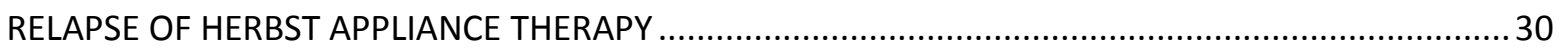

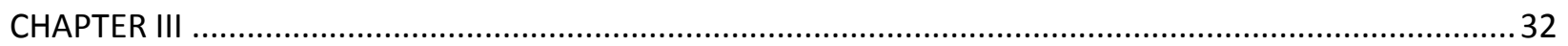

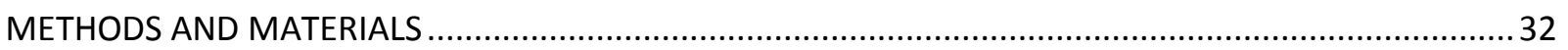

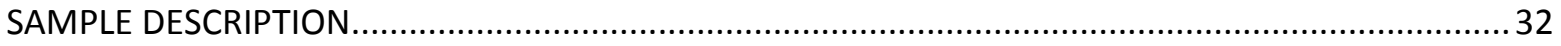

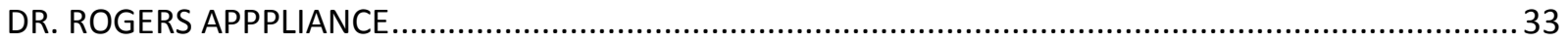

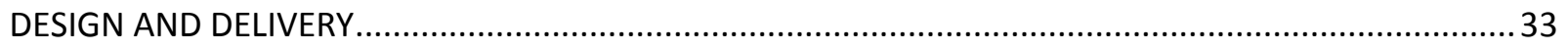

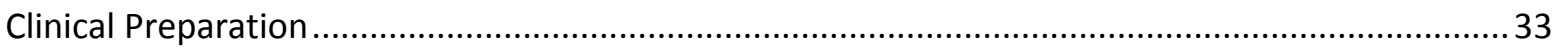



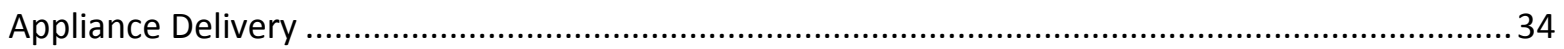

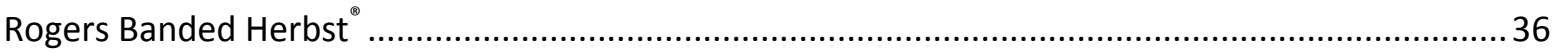

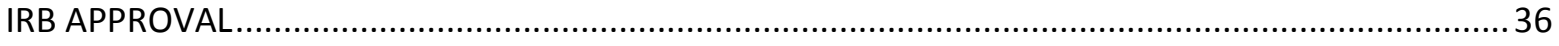

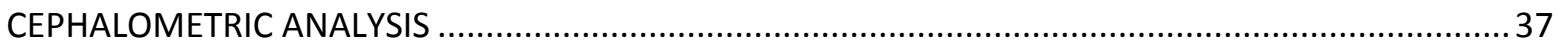

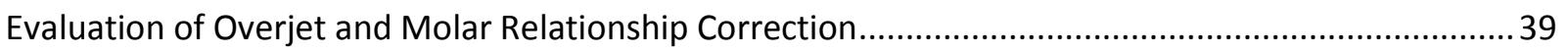

Overjet Correction $=$ Maxilla $+\mathbf{M x}$ incisor - Mandible - Md incisor ................................................... 39

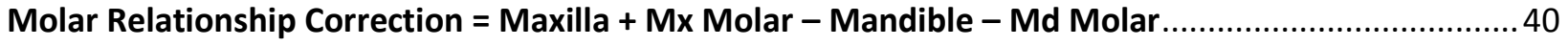

Net Overjet Correction $=$ Maxilla + Mx incisor - Mandible - Md incisor .......................................... 40

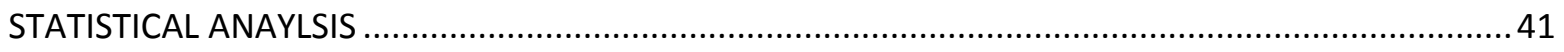

Net Molar Relationship Correction = Maxilla + Mx molar - Mandible - Md molar ............................ 41

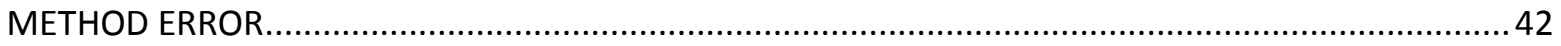

CEPHALOMETRIC LANDMARKS AND REFERENCE LINES …....................................................... 43

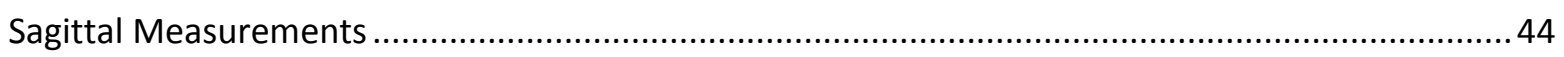

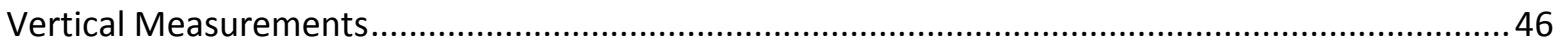

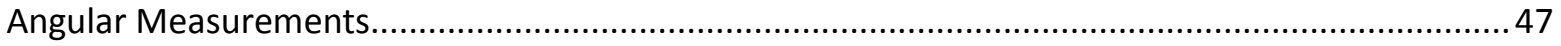

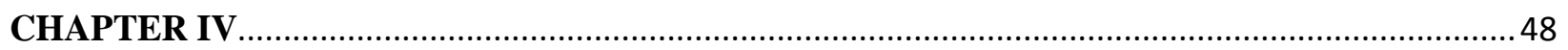

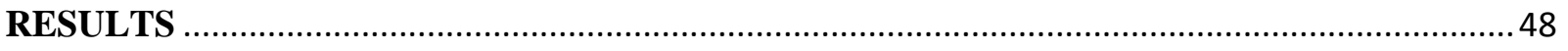

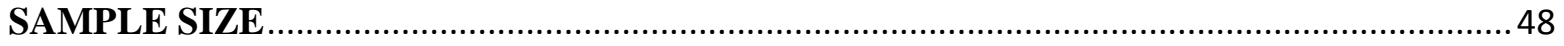

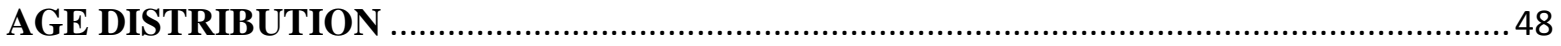

Comparison of the starting craniofacial morphology of the treatment group (T1) and the control

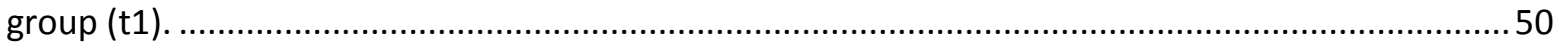

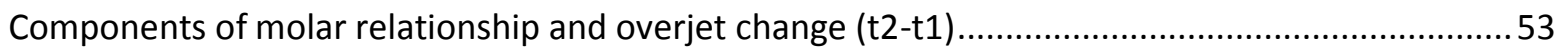

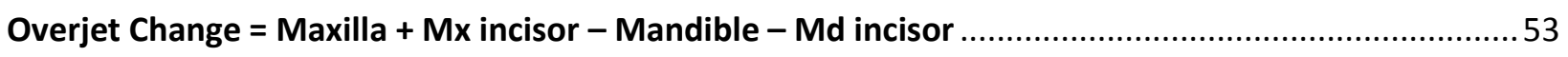








Molar Relationship Change $=$ Maxilla + Mx molar - Mandible - Md molar ........................................5 54

Changes in the control in the control group for (t2-t1) and (t3-t1) ...............................................5 55

Comparison of T2-T1 (Treatment effects of the Herbst appliance) .................................................58



Components of molar relationship and overjet correction (T2-T1) ............................................ 61

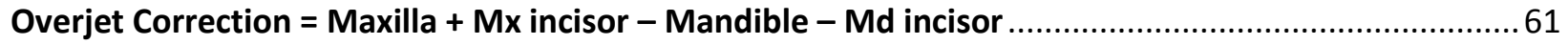

Molar Relationship Correction $=$ Maxilla + Mx molar - Mandible - Md molar ..................................61

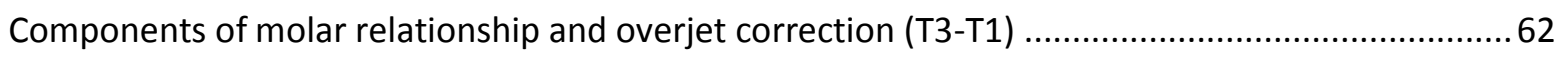

Overjet Correction $=$ Maxilla + Mx incisor - Mandible - Md incisor ................................................62

Molar Relationship Correction $=$ Maxilla + Mx molar - Mandible - Md molar ...................................62

Comparison of (T2-T1)-(t2-t1) (Treatment effects of the Herbst appliance minus growth) ..............65

Comparison of (T3-T1)-(t3-t1) (Net treatment effects minus growth) ...........................................66

Components of molar relationship and overjet correction (T2-T1) - (t2-t1) .................................68



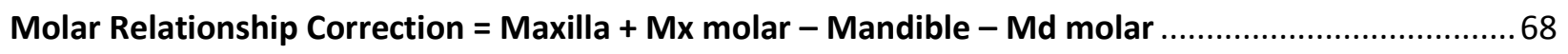

Components of molar relationship and overjet correction (T3-T1) - (t3-t1) ................................... 69

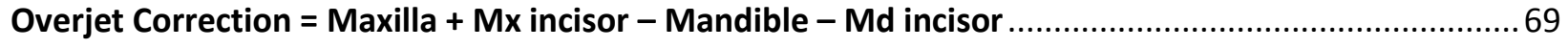

Molar Relationship Correction $=$ Maxilla + Mx molar - Mandible - Md molar ..................................69

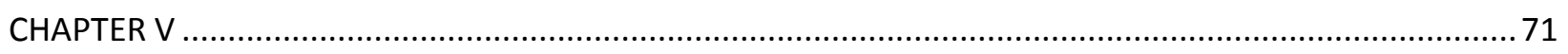



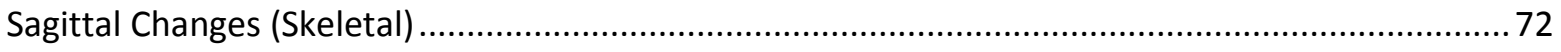

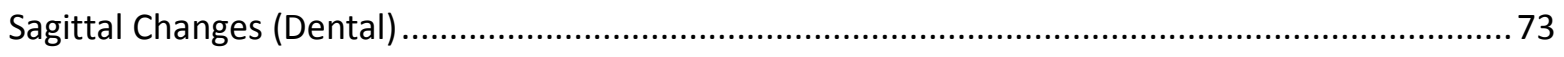

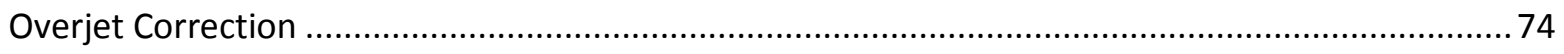

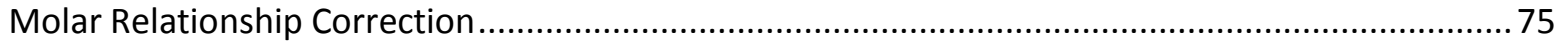

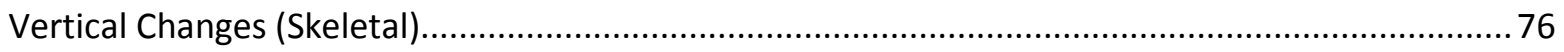

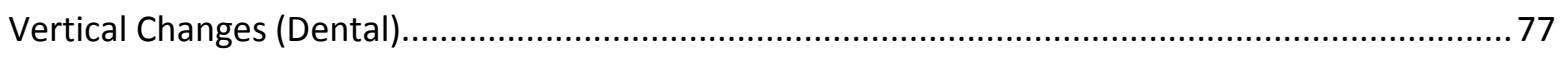

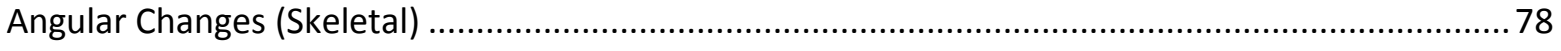

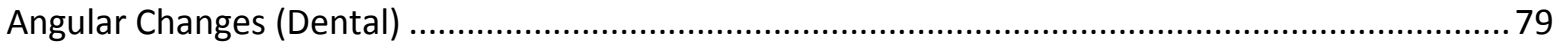

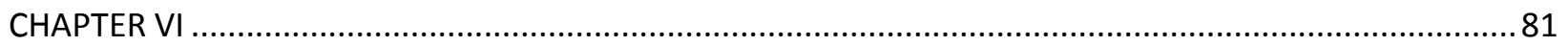






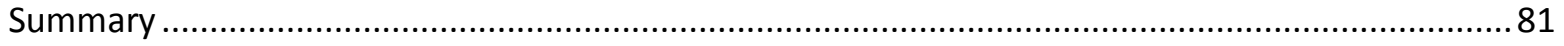

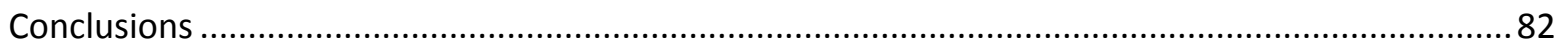

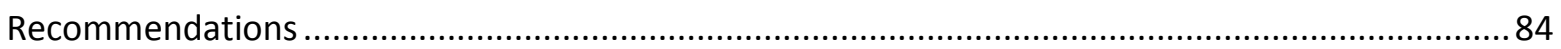

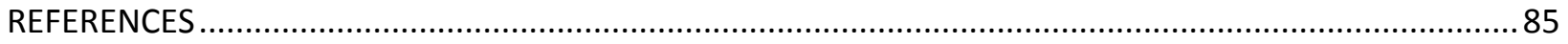

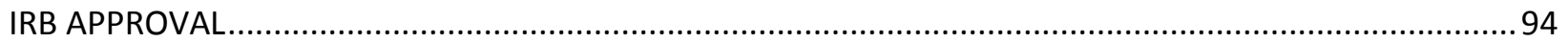




\section{LIST OF TABLES}

Table 1. Description of Timepoints used in the Study......................................................... 32

Table 2 Calculation of Overjet and Molar Relationship Changes .......................................... 39





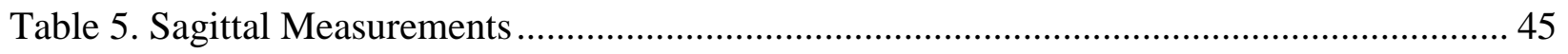

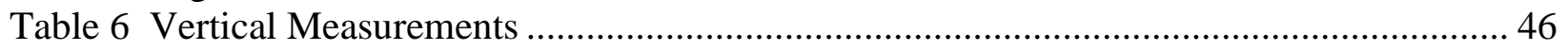



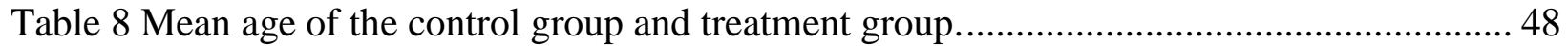

Table 9 Craniofacial morphology of the treatment group (T1) and control group (t1)............. 49

Table 10. Measurements at $\mathrm{t} 1, \mathrm{t} 2$, and $\mathrm{t} 3$ for the control group............................................ 51



Table 12.Measurements at T1, T2, and T3 for the treatment group. ..................................... 56

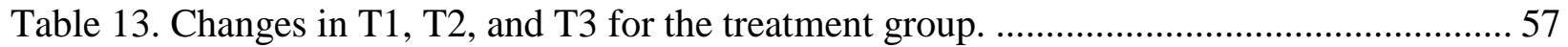






\section{LIST OF FIGURES}

Figure 1 The Rogers Banded Herbst Appliance ................................................................. 36

Figure 2. Cephalometric landmarks and reference lines for sagittal measurements.................. 45

Figure 3. Cephalometric landmarks and reference lines for vertical measurements .................. 46

Figure 4. Cephalometric landmarks and reference lines for angular measurements ................. 47

Figure 5. Components of molar relationship and overjet change between $\mathrm{t} 1$ and $\mathrm{t} 2$ for the control



Figure 6. Components of molar relationship and overjet change between $\mathrm{t} 3$ and $\mathrm{t} 1$ for the control

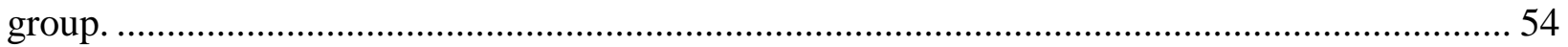

Figure 7. Components of molar relationship and overjet correction between $\mathrm{T} 1$ and $\mathrm{T} 2$ in the

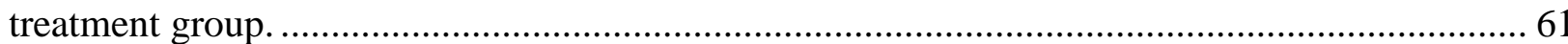

Figure 8. Components of molar relationship and overjet correction (T3-T1) .........................6 62

Figure 9. Components of molar relationship and overjet correction between T1 and T2 after



Figure 10. Components of molar relationship and overjet correction between T1 and T3 after subtracting growth changes $(\mathrm{t} 3-\mathrm{t} 1)$. 


\section{CHAPTER I \\ INTRODUCTION}

\section{BACKGROUND}

Class II malocclusion is a commonly observed clinical problem in the United States afflicting nearly one-third of the country's population ${ }^{1,2,3,4}$. The class II skeletal pattern is often derived from a multifactorial process involving genetics, function, deformities, and the size and position of facial bones ${ }^{5}$. Orthopedic functional appliances are designed to encourage sagittal mandibular growth in patients with retrognathic mandibles ${ }^{6,7,8,9}$. These orthopedic functional appliances can be either fixed or removable. The fixed functional appliances have several advantages over the removable appliances. The advantages are that no patient cooperation is required, the appliance is fixed to the dentition and therefore works 24 hours a day, and the treatment time is usually shorter often only 6 to 8 months. With removable functional appliances patient cooperation is often a problem thus prolonging treatment time to 2-4 years ${ }^{4}$.

In the early 1900s Emil Herbst was already attempting class II correction with inclined planes, however he discovered that patients would keep their mouth open in order to avoid the stress of the inclined planes ${ }^{10}$. Therefore in 1909 to keep continuous forward forces on the mandible he developed the Herbst appliance. The Herbst appliance fell out of favor in the 1930s and was pretty much forgotten until Hans Pancherz re-introduced it in $1979^{9}$. Over the years the Herbst has gained popularity and several versions of this appliance have been used ${ }^{11,12,13,14}$. 


\section{PURPOSE OF THE STUDY}

The objective of this study is to determine the amount of skeletal and dental changes of Class II adolescent patients treated with the reinforced banded Herbst appliance. The results of this research should provide additional information on appropriate placement time when using the Herbst appliance and the length of treatment required by the Herbst appliance. Cephalometric measurements were performed on radiographs and dental cast measurements were taken before any phase of treatment (T1), immediately after Herbst removal (T2), and immediately following phase II orthodontic treatment (T3). Measurements were compared to a matched control sample of untreated Class II patients from the Bolton-Brush study. The results of this study provide important information on the effectiveness of treatment with the reinforced banded Herbst appliance and offer new information on the length of time this appliance should be used. This information will thus be useful in determining the most appropriate time and length of treatment required when using the Herbst appliance for treating class II skeletal patterns. 


\section{STATEMENT OF THE PROBLEM}

What are the skeletal and dental effects associated with treatment using the reinforced banded Herbst appliance?

\section{SIGNIFICANCE OF THE PROBLEM}

There is still some controversy surrounding the use, timing, and length of time to use functional orthopedic appliances. Research has indicated that the bite jumping technique of the Herbst appliance can be used as a means of correcting Class II skeletal abnormalities by promoting growth of the mandible and remodeling of the glenoid fossa. Since Pancherz reintroduced the Herbst appliance in 1979, an increasing body of research has been published evaluating its effects on occlusion, the dentofacial complex, and the masticatory system. The result of this study will provide information on the skeletal and dental alterations of Class II patients treated with the reinforced banded Herbst appliance. The results provide valuable information that should help clinicians determine the most appropriate time and length of treatment required when using the Herbst appliance for treating class II skeletal patterns.

\section{NULL HYPOTHESIS}

1) There are no significant skeletal or dental changes following removal of the reinforced banded Herbst appliance treatment when compared to an untreated control group.

2) There are no significant skeletal or dental changes associated with Phase II comprehensive orthodontic treatment when compared to an untreated control group. 


\section{DEFINITION OF TERMS}

\section{Functional Appliance}

An appliance that is designed to exhibit force on the skeletal and dental tissues to produce alterations in position and function of the muscle and bone.

\section{Removable Functional Appliance}

A type of functional appliance that is placed in the mouth and later be taken out of the mouth by the patient.

\section{Fixed Functional Appliance}

A type of functional appliance that is placed in the mouth by the dental care provider and cannot be removed from the mouth by the patient.

\section{Herbst appliance}

A type of functional appliance that is designed to help correct patients with a class II malocclusion by forward positioning of the mandible in an effort to stimulate mandibular growth and inhibit forward maxillary growth.

\section{Bolton-Brush Study}

A longitudinal growth study performed at the Case Western University, which involved subjects with Class I, Class II, and Class III malocclusions who did not receive orthodontic treatment. These individuals were followed with orthodontic records for many years in order to chart their growth patterns.

\section{Cephalogram}

A term used as a synonym for a cephalometric radiograph. 


\section{Cephalometric analysis}

An analysis made on cephalometric radiographs comprised of a number of given landmarks and measurements used to describe positions and relationships of various skeletal components.

\section{Cephalometric radiograph}

A radiograph of the head made with precise reproducible relationships between $\mathrm{x}$-ray source, subject, and film. The generally accepted distances between x-ray source and the center of the subject are 5 feet or $150 \mathrm{~cm}$. The distance between the subject and film is usually $15 \mathrm{~cm}$, but may be standardized at a different value or varied with patient size and recorded for each exposure.

\section{Cephalometric tracing}

A tracing of selected structures from a cephalometric radiograph, made on translucent drafting paper or digitized on computer software for purposes of measurement and evaluation.

\section{Class II malocclusion}

A type of malocclusion in which the mesiobuccal cusp of the maxillary first molar is located mesial to the buccal groove of the mandibular first molar when the teeth are in centric occlusion.

\section{Class II skeletal pattern}

A type of skeletal malocclusion in which the mandible is in a retrusive position relative to the maxilla. 


\section{Retrognathic}

A term used to define the position of a skeletal component that is located in a more posterior position or relation that normal.

\section{ASSUMPTIONS}

1. The lateral cephalograms are taken with teeth in centric occlusion.

2. Without treatment, growth patterns would be similar in the experimental and control groups, which are matched in age, sex, and craniofacial morphology.

\section{LIMITATIONS}

1. This is a retrospective study of a group of patients selected from the office of Dr. Mike Rogers and Dr. Lee Andrews.

2. The experimental and control groups are selected from two different geographical sources (Lake Oswego, Oregon and Case Western Reserve University/Bolton Brush Study Center in Cleveland, Ohio, respectively).

3. Growth patterns and growth periods (peak pubertal growth period) are not available for the individuals in the study.

4. Skeletal ages of the experimental and control groups cannot be determined.

5. The experimental group was limited to patients who either had Phase I then preceded with Phase II orthodontic treatment after Phase I treatment with the Herbst appliance or who had only Phase II orthodontic treatment with the Herbst appliance.

6. The experimental group was limited to patients who had acceptable quality radiographs available for the three time points included in the study. 
7. The mechanics used in the Phase II orthodontic treatment of the experimental group were not considered in this study.

\section{DELIMITATIONS}

1. The experimental group was composed of 30 patients treated by Dr. Mike Rogers and Lee Andrews

2. Criteria of patient selection included no previous orthodontic treatment.

3. All patients in the experimental group were corrected with the reinforced banded Herbst appliance. 


\section{CHAPTER II}

\section{REVIEW OF THE LITERATURE}

\section{HISTORY AND CLASSIFICATION OF MALOCCULSION}

According to historical records the practice of orthodontics dates back at least to the Etruscans in the VIII century B.C. Specimens were found with adjustable gold bands around teeth adjacent to a space from a missing tooth. The use of orthodontics shows up again in the $4^{\text {th }}$ century B.C. in the Phoenicians for similar purposes. Malaligned teeth have been a problem plaguing humans for our entire existence ${ }^{15,16}$. A little over 150 years ago Norman Kingsley authored a text that systematically describes the practice of orthodontics. The text dates back to the 1850's and is titled, Treatise on oral deformities as a branch of mechanical surgery. The philosophy according to the text focuses on the extraction of teeth as a solution to dealing with problems of crowding and malalignment ${ }^{17}$. History indicates that Edward Angle was the first to bring attention to the need to classify malalignment. He published articles dating back to the 1890 's that develop a classification system that is still in use today ${ }^{18}$. He described these three primary types of malocclusion:

Class I - the mesiobuccal cusp of the maxillary first molar occludes with the buccal groove of the mandibular first molar, with there being a discrepancy in the line of occlusion ${ }^{18}$.

Class II- the mesiobuccal cusp of the maxillary first molar is located mesial to the buccal groove of the mandibular first molar ${ }^{18}$.

Class III- the mesiobuccal cusp of the maxillary first molar is located distal to the buccal groove of the mandibular first molar ${ }^{18}$. 


\section{ETIOLOGY OF MALOCCLUSION AND THE NEED FOR ORTHODONTIC THERAPY}

Malocclusion and dentofacial deformity can result from moderate distortions in the normal developmental process. Distortions in the normal developmental process include such conditions as hereditary influences, environmental influences, and specific causes such as embryologic developmental and skeletal growth disturbances, muscle dysfunction, acromegaly and hemimandibular hypertrophy. Without proper orthodontic treatment, these dentofacial irregularities can lead to adversity for the individuals involved including: (1) psychosocial problems associated with discrimination because of facial appearance; (2) problems with the stomatognathic system including decreased jaw function, temporomandibular joint dysfunction, and problems with mastication, swallowing, and speech; and (3) increased risk of periodontal disease, tooth decay, and trauma ${ }^{18,19}$. In addition self-esteem and quality of life can be greatly improved by orthodontic therapy.

\section{ETIOLOGY AND PRESENTATION OF CLASS II MALOCCLUSION}

As described earlier a class II malocclusion dentally is defined by the mesiobuccal cusp of the maxillary first molar being located mesial to the buccal groove of the mandibular first molar. There are two divisions of Class II malocclusion. Class II division 1 malocclusion includes maxillary incisors that are in extreme labioversion, and Class II division 2 malocclusion includes relatively normal or slightly lingually tipped incisors. A class II malocclusion can present with a dental component, a skeletal component, or mostly likely a combination of the two $^{20,21,22}$. The skeletal component is related to genetics, function, deformities, and the size and position of bones in the dentofacial complex ${ }^{23}$. A patient can present with a skeletal class II 
maolocclusion due to a deficient or retrognathic mandible, an excessive or prognathic maxilla, a deficient maxilla and mandible with the mandible being more deficient, or a combination of these $^{20,21,22}$.

\section{CLASS II SKELETAL GROWTH}

According to Enlow the facial bone components that contribute to a Class II skeletal pattern can be divided into three segments: (1) the anterior and posterior cranial base; (2) nasomaxillary complex; and (3) the ramus and corpus of the mandible. The final dentofacial form is a combined interaction of these segments that occurs during the growth process ${ }^{23}$.

\section{The Cranial Base}

The cranial base forms the floor of the cranial cavity and separates the brain from other facial structures. The 5 bones that make up the cranial base are the ethmoid, sphenoid, occipital, paired frontal, and paired temporal bones. The cranial base can be subdivided into 3 regions: the anterior, middle, and posterior cranial fossae. The primary growth of the cranial base occurs as a result of bone deposition on its outer cortex and endochondral growth at the spheno-occipital synchondrosis. A pressure adaptive growth mechanism provides a bi-directional growth direction causing displacement of facial bones ${ }^{23}$.

\section{Nasomaxillary Complex}

The nasomaxillary complex is connected to the cranial base by six pairs of sutures. The growth of the nasomaxillary complex according to Profitt ${ }^{19}$ is the result of two mechanisms. One mechanism is by means of passive displacement, resulting from growth in the cranial base. This growth provides pressure that pushes the maxilla downward and forward. This growth 
mechanism is a key element early in life, but becomes less important as the growth in the sychondrosis slows around seven years of age. The majority of the forward movement of the maxilla after age seven is due to active growth of the maxillary sutures and nose ${ }^{19}$. One can expect to see growth of about 1 to $2 \mathrm{~mm}$ per year ${ }^{19,24}$. A longitudinal cephalometric analysis study by Bishara has shown that in the majority of Class II malocclusions, the position of the maxilla was relatively normal. In cases that were not normal, the maxilla tended to be in a retrusive position more frequently than in a protrusive position indicating that the maxilla was not the major contributing factor to a Class II malocclusion ${ }^{25}$.

\section{Mandibular growth}

The growth of the mandible is the key element in most patients with a class II growth pattern since as the maxilla has been shown to be relatively normal ${ }^{25}$. Mandibular growth is also based on two mechanism, deposition and resorption. Growth of the mandible is directed in a posterior and superior direction due to this deposition and resorption of bone. As a result of this growth the condyle extends directly towards the articular surface of the glenoid fossa, which causes the entire mandible to be displaced in the opposite direction to a more forward and downward position ${ }^{26}$. The growth of the mandible occurs at a relatively stable rate before puberty. The average ramus height increases of 1 to $2 \mathrm{~mm}$ per year while the average body length experiences an increase of 2 to $3 \mathrm{~mm}$ per year ${ }^{19}$. It is these properties of mandibular growth that orthodontists must alter in hopes of providing corrective therapy for Class II malocclusions that present with a retrognathic mandible. 


\section{PREVALANCE OF CLASS II MALOCCLUSION}

About one third of the population in the United States presents with a class II malocclusion in which the mesiobuccal cusp of the maxillary first molar is located mesial to the buccal groove of the mandibular first molar. In other areas of the world such as descendants of Northern European cultures the percentages can reach as much as 30-40 percentage of the population. It has been shown that eight to ten percent of the overall population have an overjet greater than six millimeters ${ }^{27,28,29,30}$.

\section{DIAGNOSIS OF CLASS II MALOCCLUSION}

In order to provide the appropriate means of orthodontic treatment therapy one must properly diagnosis the underlying cause of the malocclusion. McNamara has outlined a means of diagnosis based on evaluating patients by components according to different planes of space ${ }^{31}$.

\section{Anteroposterior Components}

The analysis of the soft tissue profile indicates that most often patients present with a convex facial profile. The nasolabial is also considered an important indicator. Ideally, the nasoloabial angle for both males and females should be $102 \pm 8^{\circ 31}$. The anteroposterior position of the maxilla should be analyzed on a lateral cephalogram from the Sella-Nasion-Point A (SNA) angle ${ }^{33,34}$ and from Nasion perpendicular to Point $\mathrm{A}^{31}$. Also of importance is the position of the upper incisors relative to the maxilla. This can be evaluated from the distance from the facial surface of the upper incisor to a vertical line drawn perpendicular to the Frankfort horizontal plane extending through the A Point ${ }^{31}$. Ideally this measurement should be 4 to $6 \mathrm{~mm}$ in a normal individual $^{24,31,35}$. The relation of the lower incisors to the basal bone structures can be 
determined by measuring the distance from the tip of the lower incisor to the A Point-Pogonion line ${ }^{36,37}$. Mandibular position relative to the cranial base can be evaluated by measurements from the Pogonion to the nasion perpendicular ${ }^{31}$ and from the Sella-Nasion-Point B (SNB) angle ${ }^{33,34}$.

\section{Vertical Components}

The vertical skeletal dimension needs to be evaluated since this dimension may help determine the severity of the malocclusion ${ }^{37,38}$. A decrease in vertical dimension will enable the mandible to rotate upward and forward. Opposite of that are patients with an increase in vertical dimension which present with a retruded mandible, a poorly defined chin with a hyperactive mentalis muscle, and a tendency towards open bite. Vertical dimensions can be assessed on a lateral cephalogram by measuring the mandibular plane angle (MP-SN, MP-FH) and lower anterior facial height (ANS to Me $)^{22}$.

\section{Transverse Components}

The transverse relationship of the maxilla to the mandible also needs evaluated. Tollaro et al. ${ }^{39}$ have shown an underlying transverse discrepancy of $3-5 \mathrm{~mm}$ in patients with Class II malocclusion and fairly normal buccal relationships. This becomes apparent when the patient postures the mandible forward until the canines are in a class I relationship. Studies by Bacetti et al. ${ }^{40}$ Arya et al. ${ }^{41}$, and Bishara et al. ${ }^{25}$ indicate that this transverse discrepancy can be selfperpetuating and thus needs addressed. It is for similar reasons that Spillane ${ }^{42}$ and $\mathrm{McNamara}^{35}$ have recommended orthopedic rapid maxillary expansion during the adolescent years in less severe class II patients. 


\section{TREATMENT OF CLASS II MALOCCLUSION}

\section{Non-growing patient}

The amount of growth remaining is one of the most importance aspects to gauge when considering which treatment option is most favorable. If there is minimal growth or if the patient is considered non-growing then treatment option are much more limited. The options that are available for non-growing patients are: Compromised/non-extraction, extraction/camouflage, distal movement of maxillary teeth, and surgery. Many times the patient will refuse extracts and surgery which only leaves the clinician the option to straighten the teeth and leave the intra-arch discrepancy. There are limitations due to the skeletal differences and the patient will most likely be left with overjet. If the patient is open to extracts then the clinician may be able to mask a moderate skeletal discrepancy. In minor Class II malocclusions with minimal crowding the clinician may have the option of distalizing the maxillary molars. Studies have shown that about 1-2 mm of distalization may be possible ${ }^{43}$. In recent years, the Herbst appliance has been shown to be an effective modality for treating Class II malocclusions in non-growing adults ${ }^{44}$ by experiencing similar condylar growth and remodeling of the glenoid fossa that has been seen in children and adolescents ${ }^{45}$. In patients with severe class II malocclusions, orthognathic surgery often produces the best results, however it is by far the most invasive and expensive option.

\section{Growing patients}

In patient where growth modification is still possible many more treatment options are available. Clinician like to time treatment near an individual's peak pubertal growth period which occurs around age $13.9 \pm 1.0$ in males and age $11.7 \pm 1.0$ in females ${ }^{46}$. The options that 
are available for growing patients are: non-extraction/compromise, extractions, and functional appliances. Many times growth modification using functional appliances will enable treatment without extractions. Usually in growing patients extracts are indicated more for alleviating crowding then for masking skeletal discrepancies. The reason is due to the unpredictable growth of the maxilla and mandible. Functional appliances were introduced to correct problems of skeletal disharmony without surgery and many times extracts in patients with a retrognathic mandible.

\section{FUNCTIONAL APPLIANCE THERAPY TO TREAT CLASS II MALOCCLUSION}

Throughout the years many functional appliances have been developed but, Norman W. Kingsley in 1877, was the first to introduce an appliance designed to stimulate sagittal mandibular growth ${ }^{47}$. The appliances gained popularity in the 1930's with Anderson's activator and a others out of Switzerland and Germany. The fundamental logic behind these appliances were to force the lower jaw forward to stimulate mandibular growth ${ }^{19,48}$. Functional appliances can be placed into two broad categories: removable and fixed. Several problems can arise when choosing to use removable functional appliances: (1) the appliance is used only part of the day and in certain individuals the threshold for condylar growth adaptation to forward displacement may never be reached, (2) patient compliance is a problem and undetected insufficient appliance wear could produce erratic results, and (3) treatment time is relatively long, ranging anywhere from 2 to 4 years and a suitable control group is often unattainable. A fixed functional appliance offers several advantages over the removable appliance: (1) it works constantly meaning, 24 hours a day, (2) patient cooperation is not a factor, and (3) active appliance treatment time is only 6-9 months which is shorter than normal ${ }^{4}$. 


\section{THE HERBST APPLIANCE}

In the early 1900s, Emil Herbst was already repositioning mandibles forward with inclined planes, however he soon realized patients avoided the forward pressure to the lower jaw by simply keeping their mouth open. In order to prevent this he developed the Herbst appliance $^{10}$. In 1909, this new fixed bite jumping appliance was introduced to the International Dental Congress in Berlin. The appliance was designed to alter mandibular jaw and muscle function by keeping the mandible in a continuously protruded position on both jaw closure and eccentric movements ${ }^{49}$. Its design included a bilateral telescope mechanism attached by orthodontic bands to the lower first premolars and upper first molars. In 1934, Herbst published a series of articles in which he described the appliance to beneficial in treating: (1) Class II malocclusions with a retrognathic mandible; (2) mandibular ramus fractures; (3) condylectomies (used as an artificial joint); and (4) TMJ problems including crepitus and bruxism ${ }^{50}$. This appliance soon lost favor and was more or less forgotten for the next 40 years ${ }^{9,50}$.

In the early 1970's a doctor by the name, Hans Pancherz reintroduced the Herbst appliance as an experimental tool in clinical research. By the late 1970's, he had published a paper ascertaining the possibilities of stimulating mandibular growth with the appliance ${ }^{9}$. Due to the effect on the occlusion, the dentofacial complex, and the masticatory apparatus, the Herbst appliance quickly gained popularity ${ }^{9,52}$. Dr. Pancherz introduced a design that used orthodontic bands to secure the appliance to the molars. These bands were custom-made and much thicker than conventional bands ${ }^{9,51}$. Clinicians who tried to use conventional bands soon realized that the occlusal forces were too great and the bands would eventually fail. This led clinicians to development many other variations of the Herbst appliance ${ }^{11,12,13,14}$. 
Bands were eventually replaced by cobalt chromium alloy casted splints that were cemented with glass ionomer cement ensuring a precise fit on the teeth. In 1988, McNamara and Howe started using removable acrylic splint Herbst appliance, with occlusal coverage extending posteriorly from the canines to the first molars on the maxillary arch and full occlusal coverage

on the mandibular $\operatorname{arch}^{43,50}$. The bonded acrylic splint proved too difficult to remove and had the added risk of enamel decalcification. Langford introduced the crowned Herbst appliance consisting of stainless steel crowns cemented to the mandibular first premolars and maxillary first molars was introduced in the late 1980 's and early 1990 's ${ }^{11,12,53,54}$. This new crowned Herbst may have saved the appliance from abandonment and is probably considered the most popular means of retaining the appliance, but there are still draw backs. The stainless steel crowns do not adapt closely to the teeth, they have a tendency to open the bite too much and interfere with chewing, they can impinge on the gingiva, and many times can be very difficult to remove ${ }^{55}$.

\section{INDICATION FOR HERBST APPLIANCE THERAPY}

The Herbst appliance is a growth modification device and is therefore most useful in the treatment of growing individuals with both Class II, Division 1 and Class II, Division 2 malocclusions. The Herbst can however be used in non-growing individuals if the desired changes are to occur mostly in the dentoalveolar area. In addition, increased chance of developing a dual bite and TMJ problems accompany treatment in non-growing individuals ${ }^{56,57}$. The Herbst appliance can be used effectively in: post-adolescent patients, in mouth breathers, in uncooperative patients, and in patients who do not respond to treatment with removable functional appliances ${ }^{4}$. 


\section{TIMING OF HERBST APPLIANCE THERAPY}

The timing of orthopedic intervention with functional appliances somewhat controversial but most clinicians seem to agree that having the appliance in during the patients peak pubertal growth spurt is ideal ${ }^{46,58}$. Successful treatment of Class II malocclusions with functional appliances have been reported in both the early mixed dentition ${ }^{43,59}$ and the late mixed dentition $^{5,60}$. A systematic review of mandibular changes produced by functional appliances in Class II malocclusions reported that the amount of supplementary mandibular growth appears to be significantly larger if the functional treatment is performed at the pubertal peak in skeletal maturation ${ }^{61}$. The majority of the literature supports the idea that Class II correction can be successfully achieved in both the late mixed dentition and the permanent dentition. Surveys have shown that practice characteristics tend to affect orthodontists' decisions regarding orthodontic treatment and a wide range of acceptable treatment timing exists ${ }^{62}$. Studies have showen that in severe Class II cases early treatment may not be effective because often there is insufficient intercuspation and the Class II tendency tends to resurface ${ }^{63,64}$. Ultimately, the decision to include orthopedic treatment should include a conversation with the parents and the child and the individual circumstances for each patient should be considered.

\section{TREATMENT EFFECTS OF HERBST APPLIANCE THERAPY}

The Herbst appliance applies force in all three planes of space to the maxilla, the mandible, their dental counterparts, and the temporomandibular region. The Herbst appliance is considered a functional orthopedic appliance and therefore has many skeletal effects. Changes in the angular position of the palatal plane, occlusal plane, and mandibular plane are typical. Since the appliance is anchored to the teeth there are also many effects to the dentition. The 
temporomandibular joint is directly affected by treatment with the Herbst appliance, however these changes within the joint are very difficult to identify and quantify. When describing the treatment effects of the Herbst appliance, it is useful to divide it into skeletal and dental components.

\section{Skeletal Components}

Maxilla: The Herbst appliance has a restraining effect on maxillary growth similar to a headgear ${ }^{9,58,65}$. Studies have shown that growth of the maxilla in patients treated with the Herbst is consistently less than in control groups without treatment ${ }^{51,66,67,68,69,70}$. The overall size of the maxilla seems to be unaffected by treatment ${ }^{67,68,70}$. The palatal plane and occlusal plane do however experience a slight clockwise rotation ${ }^{66,68}$.

Mandible: The Herbst appliance has been shown to increase mandibular length as much as 1.3 to $3.5 \mathrm{~mm}$ over the controls during a 6-8 month period of treatment ${ }^{9,43,58,65,66,68,69,70,71,72}$. Although vertical condylar growth appears to be unaffected, the sagittal condylar growth appear to increase ${ }^{73,74}$. However a systematic review of the literature limited to randomized controlled clinical trials from 1966 to 1999 on the efficiency of functional appliances on mandibular growth by Chen et al. ${ }^{75}$ reported that there is no difference in overall mandibular change in the horizontal or vertical direction. Another systematic review by Cozza et al. ${ }^{61}$ analyzed 22 studies that met inclusion criteria in an attempt to assess the scientific evidence of functional appliances in enhancing mandibular growth in Class II subjects. Two-thirds of the samples in the 22 studies reported a clinically significant supplementary elongation in total mandibular length compared to controls (a change of greater than $2.0 \mathrm{~mm}$ in the treated groups compared to the control groups) as a result of treatment with functional appliances ${ }^{61}$. 
Temporomandibular region: The response of the temporomandibular joint to mandibular forward repositioning has been very controversial in both experimental and clinical studies. Some researchers believe that the main effect of functional appliance therapy is increased condylar growth, others feel that the main effect is due to remodeling of the glenoid fossa, and others contend that little to no structural changes occur in response to treatment ${ }^{7,8,45,76}$.

\section{Dental Components}

Maxilla: There are significant effects on the maxillary dentition in response to treatment with the Herbst appliance ${ }^{67,77}$. The maxillary molars exhibit a "high-pull headgear effect" in which they are both distalized and intruded ${ }^{9,43,51,71,78}$.

Mandible: In general, the mandibular dentition moves in an anterior direction due to Herbst treatment ${ }^{9,43,51,71,78}$. The lower incisors are proclined and intruded during treatment, however, they recline somewhat in the post-treatment phase ${ }^{68}$.

\section{RELAPSE OF HERBST APPLIANCE THERAPY}

It is well known that functional orthopedic appliances tend to have some relapse following appliance removal. The Herbst is no different. Usually at the Herbst appliance removal appointment the, the sagittal dental arch relationships are generally overcorrected and there is often incomplete cuspal interdigitation among the teeth. The active treatment time is usually around 6-8 months, the occlusion is unstable and adaptive changes will occur ${ }^{77}$. During treatment following appliance removal the maxillary molars move anteriorly, and the mandibular molars move posteriorly while the incisors becoming more upright ${ }^{4}$. Accelerated maxillary growth and a reduction in mandibular growth rates occur only minimally within the first year 
after treatment ${ }^{77}$. Usually with only dental adjustments the occlusion can settle into a Class I relationship during post-appliance treatment ${ }^{4}$. 


\section{CHAPTER III \\ METHODS AND MATERIALS}

\section{SAMPLE DESCRIPTION}

\section{Experimental Group}

This group consisted of thirty patients consecutively treated with the reinforced banded Herbst appliance by Dr. Mike Rogers and Dr. Lee Andrews at their private practice in Augusta, GA. The stage of dental development varied from early to late mixed dentition to early permanent dentition. The treated sample was evaluated for skeletal and dental changes immediately following Herbst appliance removal (T2) and immediately following completion of phase II treatment (T3). Lateral cephalograms and dental casts were taken at T1, T2, and T3. Symbols used to represent the different time intervals are illustrated in Table 1.

Table 1. Description of Timepoints used in the Study

\begin{tabular}{|c|l|}
\hline T1 & Before any Phase of Treatment \\
\hline T2 & Immediately Following Herbst Appliance Removal \\
\hline T3 & At the Completion of Phase II Treatment \\
\hline T2-T1 & Changes from appliance treatment \\
\hline T3-T1 & Total changes from growth and appliance \\
\hline
\end{tabular}




\section{DR. ROGERS APPPLIANCE DESIGN AND DELIVERY}

\section{Clinical Preparation}

Facial and lingual cleats should be prewelded to the bands to serve as guides for accurately positioning the bands in the alginate impression. The bands are then fitted to the maxillary and mandibular molars.

Before the wax bite is registered, have the patient practice in front of a mirror. The patient will typically bite with the incisors edge-to-edge. If a skeletal midline discrepancy exists, the patient should be encouraged to align the midlines while the wax bite is taken. If there is a dental midline discrepancy, its correction can be completed after the Herbst is removed and full brackets are placed. If the pretreatment overjet is $6 \mathrm{~mm}$ or more, take the bite registration short of the edge-to-edge position and then advance the mandible in gradual increments.

Alginate impressions are made of the arches, and the bands are cemented in place in the alginate with super glue. The impressions should be poured with dental stone as soon as possible. A laboratory prescription is completed including any special features the clinician may need in the Herbst construction. The prescription, the wax bite, and the plaster casts containing the bands are forwarded to the laboratory.

Brackets are bonded to the maxillary incisors at this appointment, and a sectional wire is placed to align those teeth before the Herbst is delivered at the next appointment. This is particularly helpful with Class II, division 2 patients whose incisors need alignment and advancement. The molars should be separated about a week before delivery of the appliance to provide adequate band space ${ }^{55}$. 


\section{Laboratory Construction}

Although the .010" bands are less likely to split than conventional bands, .051" reinforcing wires should be soldered to the distal occlusal margins of the mandibular bands to give them even more bulk and strength. The mandibular bands are connected with an .051" lingual arch. In addition, .025" wires are soldered to the mesial occlusal margins of the mandibular and maxillary bands, and $.045 "$ reinforcing wires are soldered to the distal occlusal margins of the maxillary bands. Finally, .022" X .028" tubes are soldered to an .045" stainless steel wire mesial to the maxillary molar pivots, permitting archwires to be used for alignment and control of the maxillary anterior segment.

This design does not require occlusal rests on the second molars, because the support wire soldered to the distal surfaces of the maxillary bands prevents overeruption of the second molars. Although some have tried to use a cantilever Herbst design with bands, they have reported excessive breakage ${ }^{55}$.

\section{Appliance Delivery}

When the initial band fitting, wax-bite registration, impressions, and seating of the bands into the impressions have been done correctly, appliance delivery becomes a predictable 30-minute appointment. The appliance is tried in the mouth before cementation, with the rods and tubes inspected for proper length and to make sure they do not impinge on the ascending rami, which are now advanced. The $.051 "$ mandibular lingual arch should lie no more than $.5 \mathrm{~mm}$ from the mandibular incisors. Excess length of the rods and tubes can be indicated with a permanent marker for subsequent cutting with a heatless stone. 
Once the fit is satisfactory, the appliance is removed and dried. The screws and tubes to the maxillary pivots are then secured by placing Ceka Bond on the screw threads, ensuring that the screws will not back out during treatment.

Prior to cementation, the molars are pumiced and cleaned as usual and etched with $\underline{\mathrm{GC}}$ Ortho Conditioner, a 10\% polyacrylic acid solution. Using Fuji I band cement, the maxillary molar bands are cemented to the teeth with the tubes attached to the pivots. The mandibular bands can be cemented more easily without the rods attached. Immediately after the bands are firmly seated, the excess cement should be brushed away with a disposable toothbrush. This saves considerable clean-up time and is more comfortable for the patient.

When arch development is needed, maxillary or mandibular rapid palatal expanders can be added to the Herbst appliance. The maxillary RPE should be turned once a day until the desired expansion is achieved; the mandibular screw is turned every other day. Once the expansion has been completed, the screws are secured with light-cured acrylic. Thumb cribs or tongue prongs for habit control can also be easily incorporated into this Herbst design.

An advantage of the Herbst is that patients and parents can immediately see an improvement in the facial profile, which boosts their enthusiasm and cooperation. One of the greatest advantages with this design, however, is its ease of removal when the Herbst phase of treatment is finished. The mandibular rods are removed first, while the upper tubes are left attached. The mandibular arch and bands are then taken out with a band-removing plier. The maxillary anterior brackets, archwire, and bands are removed as a unit, reducing the risk of the patient's swallowing a band ${ }^{55}$. 


\section{Rogers Banded Herbst ${ }^{\circledR}$}

Dr. Mike Rogers has been instrumental in promoting the Banded Herbst ${ }^{\circledR}$. He modified the standard Banded Herbst ${ }^{\circledR}$ by eliminating the transpalatal arch for added comfort. For stability, double buccal archwire tubes are incorporated on the upper and a larger .051" lingual arch is used on the lower. Second molar rests are added if the molars are erupting ${ }^{55}$.
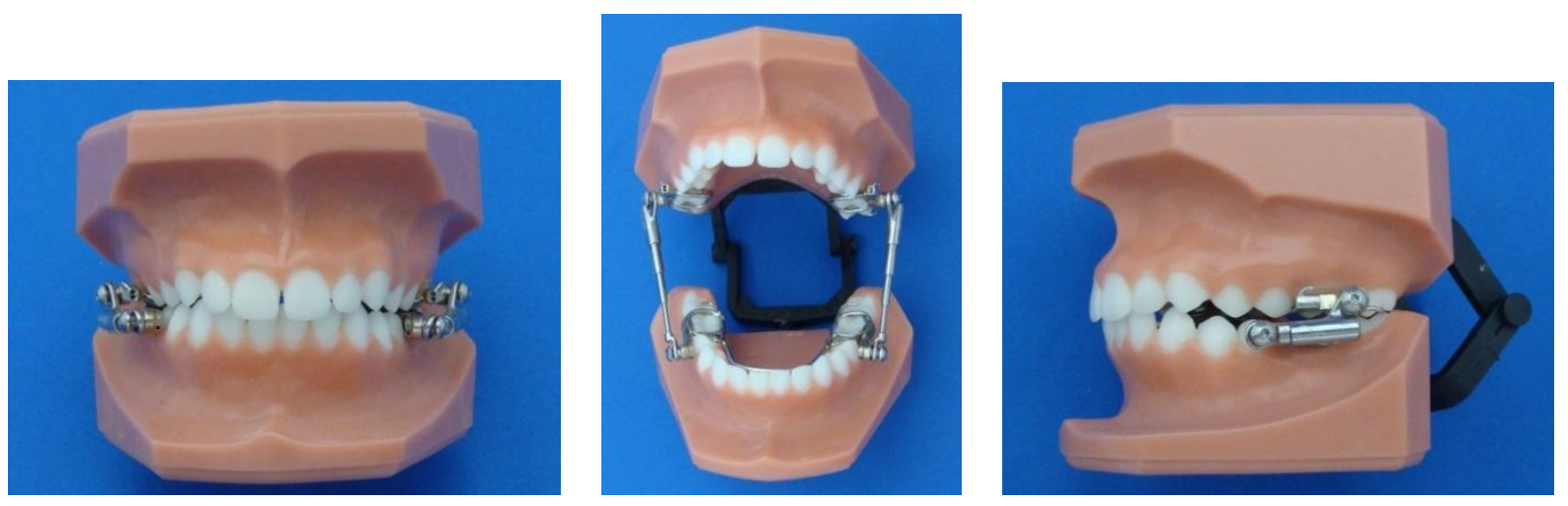

Figure 1 The Rogers Banded Herbst Appliance

\section{IRB APPROVAL}

IRB exemption was obtained from West Virginia University prior to beginning the study. Approval was obtained from both Dr. Mike Rogers and Dr. Lee Andrews. The data for the control sample was obtained from research done by Dr. Tim Wigal and Dr. Peter Ngan from their use of the Case Western University orthodontic records and the Bolton-Brush Study cephalograms. (Appendix A) 


\section{CEPHALOMETRIC ANALYSIS}

Lateral cephalograms were obtained from the office of Dr. Mike Rogers and Lee Andrews for the experimental subjects before any Phase of treatment (T1), immediately following Herbst appliance removal (T2), and at the completion of Phase II treatment (T3). The radiographs were in digital format then uploaded into Dolphin Imaging software (Patterson Technology, Chatsworth, CA) and traced digitally to ensure a 1:1 conversion. The lateral cephalometric images where then printed out on a Lexmark C510 Printer (Lexmark International, Lexington, KY) using photographic paper.

Digital copies of the lateral cephalograms matched closely in age, sex, and craniofacial morphology with the treatment subjects were obtained from the Bolton-Brush Study at Case Western Reserve University in Cleveland, $\mathrm{OH}$ and were used as the control subjects. The images were scanned at 12 bit grayscale resolution with a spatial resolution of $0.1 \mathrm{~mm}$ per pixel and stored in uncompressed TIFF format. The images were converted to JPEG format with the IrfanView software (Version 4.0) and loaded into Adobe Photoshop 6.0 (Adobe Systems, San Jose, California) for size analysis. All original radiographs from the Bolton Study were indexed with 4 corner fiduciary points using a template according to the method described by Baumrind and Miller ${ }^{107}$. Within Adobe Photoshop, the resolutions of the images were verified (600dpi), and the images were resized to the original dimensions of the unscanned radiographs. Printouts were then made on a Lexmark C510 Printer (Lexmark International, Lexington, KY) and the fiduciary points were measured with an electronic digital caliper to ensure a 1:1 conversion with no distortion from the original radiographs. 
Tracings were performed on printouts obtained from the digitized cephalograms by one operator using a \#2 $\mathrm{HB}$ mechanical lead pencil (Pentel $0.5 \mathrm{~mm}$ lead), an orthodontic protractor, and 0.003 inch matte cephalometric acetate tracing film (3M Unitek, Monrovia, CA). A custom cephalometric analysis was performed utilizing landmarks correlating with the cephalometric systems described by Bjork ${ }^{79}$, Pancherz ${ }^{80}$, Van Laecken ${ }^{81}$ and Wigal ${ }^{82}$. The data was normalized to account for magnification differences between the cephalometric machine used for the Bolton Brush Study (5.6\%) and the cephalometric machine used at the office of Dr. Mike Rogers and Lee Andrews.

The measurement for each angular variable was performed with the use of a cephalometric protractor and evaluated to the nearest 0.5 degree. The measurement for each sagittal and vertical measurement was performed with an electronic digital caliper and evaluated to the nearest $0.01 \mathrm{~mm}$. The caliper was calibrated to $0.0 \mathrm{~mm}$ prior to each measurement. Because lateral cephalograms often present landmarks with right and left images, the midpoint bisecting the two images was used. 


\section{Evaluation of Overjet and Molar Relationship Correction}

To determine the amount of skeletal and dental contribution to the overjet and molar relationship correction, the amount of dental change in the maxilla and mandible were calculated. The method of calculation is shown below (Table 11).

Table 2 Calculation of Overjet and Molar Relationship Changes
\begin{tabular}{|c|c|}
\hline \multicolumn{1}{|c|}{ Overjet } & Molar Relationship \\
\hline Skeletal contributions: & Skeletal contributions: \\
1. OLp-Apt & 1. OLp-Apt \\
2. OLP-Pg & 2. OLP-Pg \\
Dental contributions: & Dental contributions: \\
3. Is-OLp minus OLp-Apt & 3. Ms-OLp minus OLp-Apt \\
4. Ii-OLp minus OLp-Pg & 4. Mi-OLp minus OLp-Pg \\
Overjet correction: & Molar relationship correction: \\
Sum of $1,2,3$,and 4 & Sum of $1,2,3$, and 4 \\
& \\
\hline
\end{tabular}

When adding figures from the above table, the following formula was used for overjet correction:

$$
\text { Overjet Correction }=\text { Maxilla }+ \text { Mx incisor }- \text { Mandible }- \text { Md incisor }
$$

$$
\begin{aligned}
& \text { Maxilla }=\text { OLp-A pt. } \\
& \text { Mx incisor }=\mathrm{Is}-\mathrm{OLp} \text { minus OLp-A pt. } \\
& \text { Mandible }=\mathrm{OLp}-\mathrm{Pg} \\
& \text { Mandibular incisor = li-OLp minus OLP-Pg }
\end{aligned}
$$


When adding figures from the above table, the following formula was used for molar

$$
\text { Molar Relationship Correction = Maxilla }+ \text { Mx Molar }- \text { Mandible }- \text { Md Molar }
$$

relationship correction or increase;

$$
\begin{aligned}
& \text { Maxilla }=\text { OLp-A pt. } \\
& \text { Maxillar molar = Ms-OLp minus OLp-A pt. } \\
& \text { Mandible }=\text { OLp-Pg } \\
& \text { Mandibular molar = Mi-OLp minus OLp-Pg }
\end{aligned}
$$

Net Overjet/Molar Relationship Changes: When determining the net treatment effect of overjet and molar relationship correction, the control group figures were subtracted from the treated group. Calculations were made for the treatment group minus the control group at various time periods and the same formulas were used to calculate net overjet and net molar relationship correction or change:

Net Overjet Correction $=$ Maxilla + Mx incisor - Mandible - Md incisor

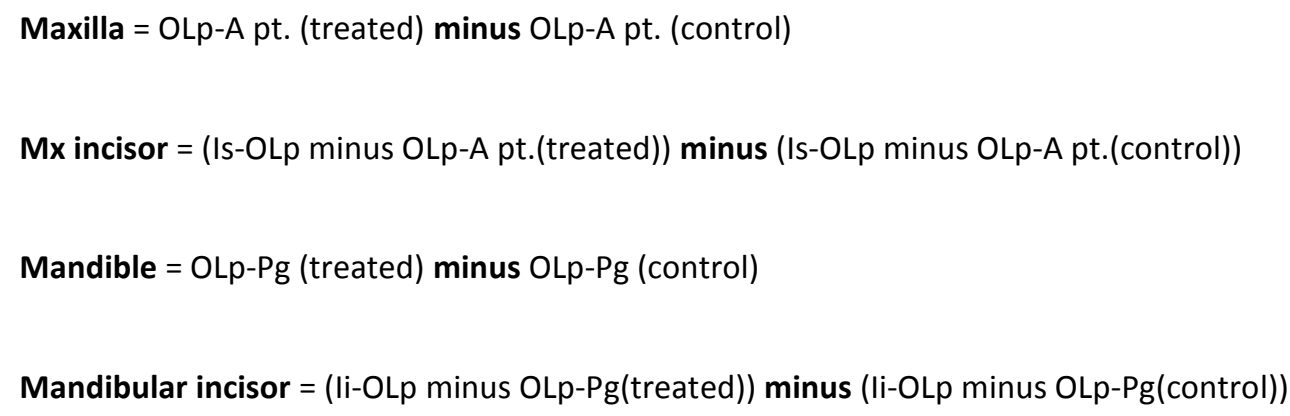


When comparing the treated and control subjects for net molar relationship correction the following formula was used:

Net Molar Relationship Correction $=$ Maxilla + Mx molar - Mandible - Md molar

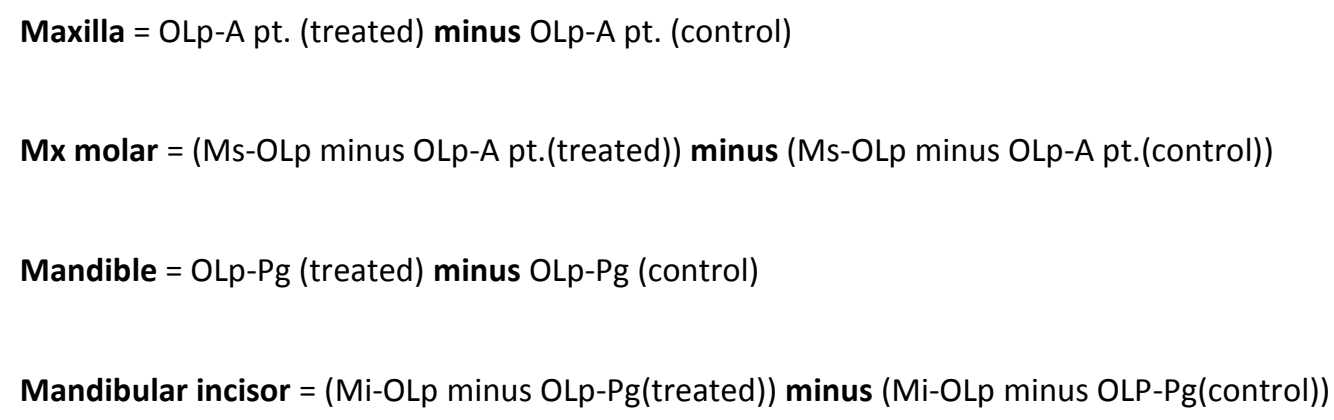

\section{STATISTICAL ANAYLSIS}

The starting forms of the control and experimental samples were compared using a matched pairs t-test. The skeletal and dental difference between the treatment and control subjects for each variable across the three time periods (T1, T2, and T3) was analyzed. A matched pairs t-test was performed for each variable to identify treatment effects of the Herbst appliance, growth, and Herbst appliance plus growth (T2-T1), (T3-T2), and (T3-T1). A matched pairs t-test was also used to analyze (T2-T1)-(t2-t1), (T3-T2)-(t3-t2), and (T3-T1)-(t3-t1). A level of significance of $\mathrm{p}<0.05$ (95\% confidence interval) was used in this study. 


\section{METHOD ERROR}

The reliability of the cephalometric measurements was tested by investigating the error in locating, superimposing, and measuring the changes of all landmarks. Ten patients were randomly selected and for both, lateral cephalometric and dental cast, all measurements for all time points (T1, T2, and T3) were made at least two weeks after the initial tracing and analyzed to evaluate error. The intraclass correlation coefficient of reliability $(\mathrm{R})$ was used to determine the reliability of cephalometric measurements. The $\mathrm{R}$ value ranged from 0 to 1.00 with $\mathrm{R}$ value greater than 0.90 indicating high reliability. The correlations of all the cephalometric variables ranged from 0.96 to 0.99 , with most being above 0.98 . The method of cephalometric analysis used in this study was deemed to be reliable and repeatable. 


\title{
CEPHALOMETRIC LANDMARKS AND REFERENCE LINES
}

\author{
The cephalometric systems described by Bjork ${ }^{79}$, Pancherz $^{80}$, Van Laecken $^{81}$ and Wigal ${ }^{82}$
}

were used in this study. The landmarks are defined in Table 2 . The reference lines that were

used are defined in Table 3. The measurements for this study were grouped into three categories:

sagittal, vertical, and angular.

Table 3. Skeletal and Dental Landmarks

\begin{tabular}{|c|c|c|}
\hline Symbol & Name & Definition \\
\hline Ii & Incison inferious & The incisal point of the most prominent mandibular central incisor \\
\hline Is & Incison superious & The incisal point of the most prominent maxillary central incisor \\
\hline Iia & Mandibular incisor apex & The root apex of the most prominent mandibular central incisor \\
\hline Isa & Maxillary incisor apex & The root apex of the most prominent maxillary central incisor \\
\hline Mi & Molar inferious & The mesial contact point of the mandibular permanent first molar \\
\hline Mic & $\begin{array}{l}\text { Molar inferious mesial } \\
\text { cusp }\end{array}$ & The mesio-buccal cusp tip of the mandibular first molar \\
\hline Ms & Molar superious & The mesial contact point of the maxillary permanent first molar \\
\hline Msc & $\begin{array}{l}\text { Molar superious mesial } \\
\text { cusp }\end{array}$ & The mesio-buccal cusp tip of the maxillary first molar \\
\hline Co & Condylion & The most supero-posterior point on the curvature of the condylar head \\
\hline $\mathrm{Pg}$ & Pogonion & The most prominent point of the chin \\
\hline ANS & Anterior Nasal Spine & The apex of the spina nasalis anterior \\
\hline A pt. & Subspinale & $\begin{array}{l}\text { The deepest point in the concavity of the anterior maxilla between the ANS } \\
\text { and alveolar crest }\end{array}$ \\
\hline PNS & Posterior Nasal Spine & $\begin{array}{l}\text { The most posterior point on the contour of the palate in the midsagittal } \\
\text { plane }\end{array}$ \\
\hline $\mathrm{Me}$ & Menton & The deepest point of the mandibular symphysis \\
\hline Go & Gonion & The lowest point of the bony contour of the angle of the mandible \\
\hline S & Sella & The center of Sella turcica \\
\hline $\mathrm{N}$ & Nasion & The most anterior point of the nasofrontal suture \\
\hline B pt. & Supramentale & $\begin{array}{l}\text { The innermost point on the contour of the mandible between the incisor } \\
\text { tooth and the bony chin }\end{array}$ \\
\hline Gn & Gnathion & The center of the inferior point on the mandibular symphysis \\
\hline
\end{tabular}


Table 4. Definition of reference lines

\begin{tabular}{|l|l|l|}
\hline Symbol & \multicolumn{1}{|c|}{ Name } & \multicolumn{1}{c|}{ Definition } \\
\hline NSL & Sella-Nasion Line & Reference line joining Nasion and Sella \\
\hline OL & Occlusal Line & $\begin{array}{l}\text { Reference line joining the maxillary incisal edge and the } \\
\text { molar superious mesial cusp tip }\end{array}$ \\
\hline OLp & $\begin{array}{l}\text { Occlusal Line } \\
\text { Perpendicular }\end{array}$ & $\begin{array}{l}\text { Reference line produced by dropping a perpendicular line } \\
\text { from sella to the occlusal plane }\end{array}$ \\
\hline OLs & Occlusal Line Sella & $\begin{array}{l}\text { Reference line parallel to OL passing through sella } \\
\text { (perpendicular to OLp passing through sella) }\end{array}$ \\
\hline NL & Maxillary Line & $\begin{array}{l}\text { Reference line joining anterior nasal spine and posterior nasal } \\
\text { spine }\end{array}$ \\
\hline ML & Mandibular Line & Reference line joining menton and gonion \\
\hline
\end{tabular}

\section{Sagittal Measurements}

Analysis of the sagittal skeletal and dental changes were performed using a reference grid from T1 lateral cephalogram based on the occlusal line (OL) and occlusal line perpendicular (OLp). (Figure 2). This reference grid was used for all sagittal measurements. The reference grid from $\mathrm{T} 1$ was transferred to $\mathrm{T} 2$, and $\mathrm{T} 3$ radiographs by superimposition on the anterior cranial base. Measurements were taken from OLp to designated landmarks as well as four other measurements: Condylion—A pt (Co-Apt); Condylion—Gnathion (Co-Gn); Condylion— Gnathion minus Condylion-A pt. (Co-Gn minus Co-Apt). In total, there were nine sagittal measurements recorded for each cephalogram (Table 4). 
Table 5. Sagittal Measurements

\begin{tabular}{|l|l|}
\hline \multicolumn{1}{|c|}{ Variables } & \multicolumn{1}{c|}{ Definition } \\
\hline Skeletal measuring points: & \\
\hline OLp-A pt. & Position of maxillary base \\
\hline OLp-B pt. & Position of mandibular base \\
\hline OLp-Pg & Position of madibular base \\
\hline OLp-Co & Position of Condyle \\
\hline Dental measuring points: & \\
\hline Is-OLp & Position of maxillary central incisor \\
\hline Ii-OLp & Position of mandibular incisor \\
\hline Is-OLp minus Ii-OLp & Overjet \\
\hline Ms-OLp & Position of maxillary first permanent molar \\
\hline Mi-OLp & Position of mandibular first molar \\
\hline
\end{tabular}

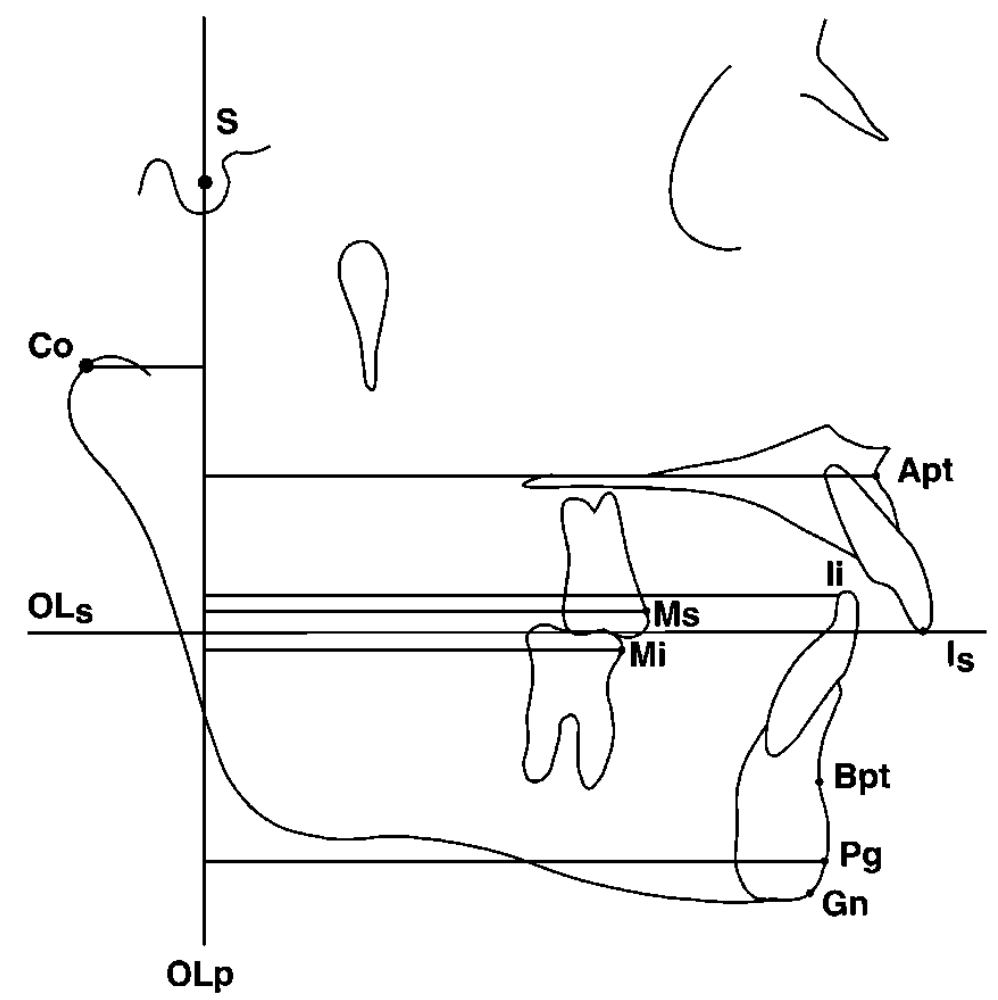

Figure 2. Cephalometric landmarks and reference lines for sagittal measurements 


\section{Vertical Measurements}

The reference lines that were used for vertical measurements included OLs, NL, ML, and OL (Figure 3). OLs was obtained from the T1 radiograph and transferred by superimposition on the anterior cranial base to the $\mathrm{T} 2$, and $\mathrm{T} 3$. The seven variables are listed in Table 5.

Table 6 Vertical Measurements

\begin{tabular}{|l|l|}
\hline \multicolumn{1}{|c|}{ Variables } & \multicolumn{1}{c|}{ Definition } \\
\hline Skeletal measuring points: & \\
\hline OLs-A pt. & Maxillary vertical position \\
\hline ANS-Me & Lower facial height \\
\hline Dental measuring points: & \\
\hline Is-NL & Position of maxillary central incisor \\
\hline Ii-ML & Position of mandibular central incisor \\
\hline Overbite & Distance from Ii perpendicular To OL \\
\hline Msc-NL & Position of maxillary permanent first molar \\
\hline Mic-ML & Position of mandibular permanent first molar \\
\hline
\end{tabular}

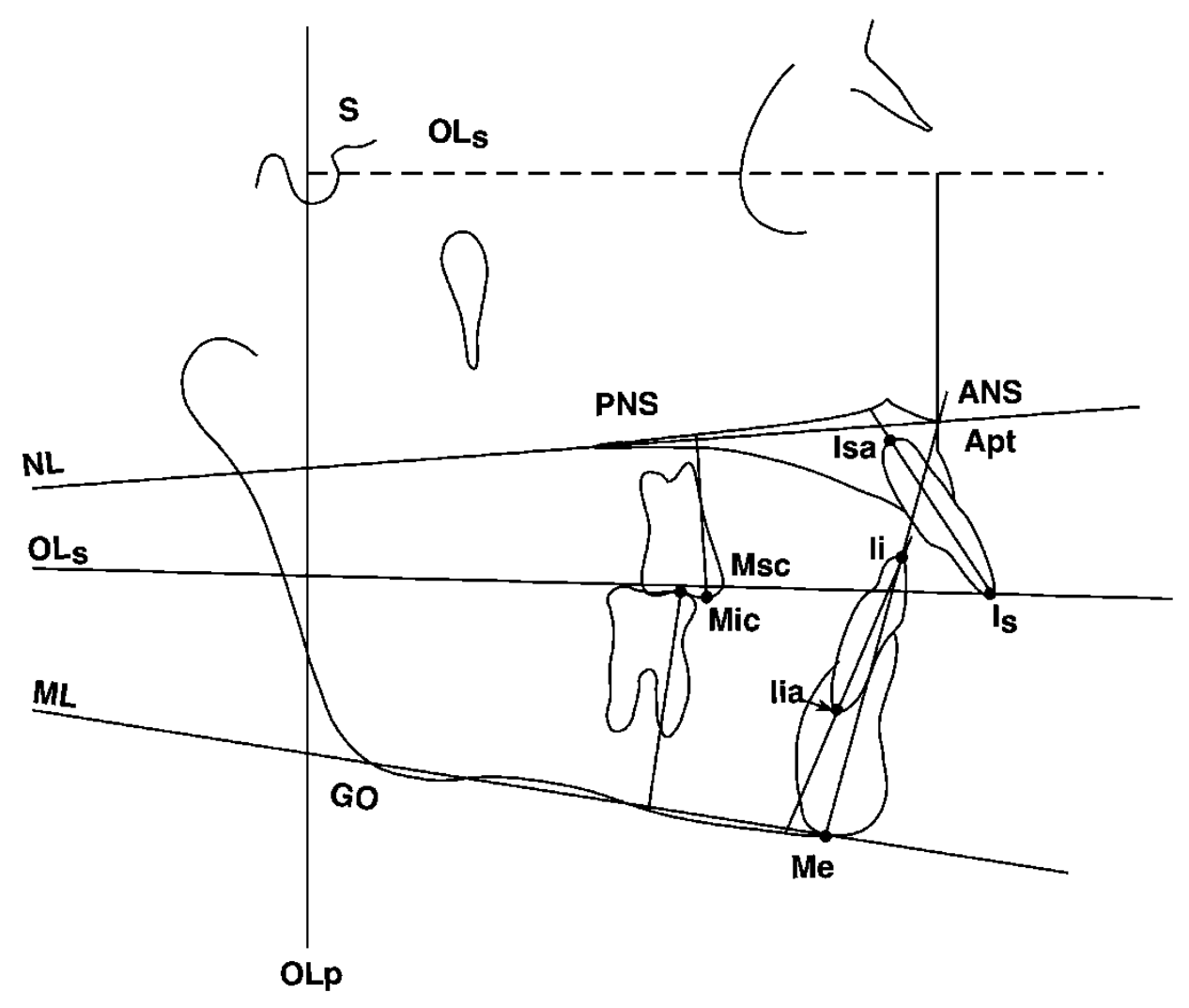

Figure 3. Cephalometric landmarks and reference lines for vertical measurements 


\section{Angular Measurements}

Angular measurements were used to identify changes in the dentofacial complex (Table

6). Cephalometric landmarks and reference lines for angular measurements are illustrated in

Figure 4.

Table 7 Angular Measurements

\begin{tabular}{|l|l|}
\hline \multicolumn{1}{|c|}{ Variables } & \multicolumn{1}{|c|}{ Definition } \\
\hline Skeletal measuring points: & \\
\hline SNA & Maxillary base relative to SNL \\
\hline SNB & Mandibular base relative to SNL \\
\hline ANB & SNA minus SNB \\
\hline SNL-NL & Palatal plane angle \\
\hline SNL-ML & Mandibular plane angle \\
\hline SNL-OLf & Occlusal plane angle (Functional occlusal plane) \\
\hline Wits & Position of the maxillary base relative to the mandibular base \\
\hline Dental measuring points: & \\
\hline Is/NL & Maxillary central incisor angle \\
\hline Ii/ML & Mandibular central incisor angle \\
\hline
\end{tabular}



Figure 4. Cephalometric landmarks and reference lines for angular measurements 


\section{CHAPTER IV RESULTS}

\section{SAMPLE SIZE}

The control (t1, t2, t3) and treatment (T1, T2, and T3) groups each consisted of 30 patients.

\section{AGE DISTRIBUTION}

The age of the treatment and control groups were matched closely. The mean age of the treatment group at T1 was 12.34 years. The mean age of the control group at $\mathrm{t} 1$ was 10.40 years. The mean age of the treatment group at T2 was 13.88 years. The mean age of the control group at $\mathrm{t} 2$ was 13.00 years. The mean age of the treatment group at T3 was 15.66 years. The mean age of the control group at $\mathrm{t} 3$ was 14.70 years.

Table 8 Mean age of the control group and treatment group.

\section{Control}

10.40

13.00

14.70
Treatment

12.34

13.88

15.66 
Table 9 Craniofacial morphology of the treatment group (T1) and control group (t1).

\begin{tabular}{|c|c|c|c|c|c|c|c|}
\hline \multirow{2}{*}{ Variable } & \multicolumn{2}{|c|}{ T1 } & \multicolumn{2}{c|}{ t1 } & \multirow{2}{*}{ Mean } & P value & Significance \\
\cline { 2 - 6 } & & Mean & S.D. & Mean & S.D. & Difference & \\
\hline Sagittal: & & & & & & & \\
\hline Olp-Co & $\mathbf{9 . 3 2}$ & 2.85 & $\mathbf{1 0 . 0}$ & 2.2 & -0.68 & 0.1788 & NS \\
\hline Olp-A pt & $\mathbf{7 3 . 5 9}$ & 4.72 & $\mathbf{7 0 . 3}$ & 4.2 & 3.29 & 0.1635 & NS \\
\hline Olp-Ms & $\mathbf{5 0 . 7 6}$ & 4.46 & $\mathbf{4 9 . 2}$ & 3.8 & 1.56 & 0.2327 & NS \\
\hline Olp-Mi & $\mathbf{5 0 . 9 0}$ & 4.62 & $\mathbf{4 9 . 0}$ & 4.3 & 1.9 & 0.2767 & NS \\
\hline Olp-Is & $\mathbf{8 1 . 6 3}$ & 5.20 & $\mathbf{7 7 . 2}$ & 5.5 & 4.43 & 0.3368 & NS \\
\hline Olp-li & $\mathbf{7 4 . 8 5}$ & 5.27 & $\mathbf{7 1 . 9}$ & 4.8 & 2.95 & 0.4952 & NS \\
\hline Olp-Pg & $\mathbf{7 5 . 4 7}$ & 6.02 & $\mathbf{7 3 . 9}$ & 4.8 & 1.57 & 0.7232 & NS \\
\hline Vertical: & & & & & & & \\
\hline OLs-Apt & $\mathbf{3 0 . 8 5}$ & 3.37 & $\mathbf{2 6 . 9}$ & 2.2 & 3.95 & 0.8119 & NS \\
\hline ANS-Me & $\mathbf{5 7 . 8 6}$ & 4.94 & $\mathbf{5 9 . 0}$ & 5.1 & -1.14 & 0.9519 & NS \\
\hline Is-NL & $\mathbf{2 6 . 8 8}$ & 3.05 & $\mathbf{2 6 . 0}$ & 2.6 & 0.88 & 0.9769 & NS \\
\hline Ii-ML & $\mathbf{3 7 . 0 1}$ & 3.10 & $\mathbf{3 5 . 4}$ & 3.3 & 1.61 & 0.9682 & NS \\
\hline Overbite & $\mathbf{4 . 4 4}$ & 1.44 & $\mathbf{3 . 1}$ & 1.4 & 1.34 & 0.8677 & NS \\
\hline Msc-NL & $\mathbf{1 9 . 5 6}$ & 2.04 & $\mathbf{1 8 . 5}$ & 2.0 & 1.06 & 0.7854 & NS \\
\hline Mic-ML & $\mathbf{2 6 . 5 1}$ & 2.50 & $\mathbf{2 7 . 0}$ & 2.4 & -0.49 & 0.7226 & NS \\
\hline Angular: & & & & & & & \\
\hline SNA & $\mathbf{8 2 . 8 8}$ & 4.75 & $\mathbf{8 0 . 1}$ & 2.8 & 2.78 & 0.7538 & NS \\
\hline SNB & $\mathbf{7 7 . 1 7}$ & 3.70 & $\mathbf{7 5 . 8}$ & 2.9 & 1.37 & 0.5209 & NS \\
\hline ANB & $\mathbf{5 . 7 1}$ & 2.15 & $\mathbf{4 . 3}$ & 1.3 & 1.41 & 0.2954 & NS \\
\hline SNL-NL & $\mathbf{6 . 2 0}$ & 3.86 & $\mathbf{6 . 4}$ & 2.9 & -0.2 & 0.0877 & NS \\
\hline SNL-ML & $\mathbf{2 9 . 5 2}$ & 4.87 & $\mathbf{3 3 . 4}$ & 4.8 & -3.88 & 0.0923 & NS \\
\hline SNL-OLs & $\mathbf{1 5 . 6 9}$ & 4.14 & $\mathbf{1 9 . 9}$ & 3.1 & -4.21 & 0.0937 & NS \\
\hline Is/NL & $\mathbf{1 1 2 . 4 7}$ & 9.29 & $\mathbf{1 1 0 . 0}$ & 5.0 & 2.47 & 0.1041 & NS \\
\hline Ii/ML & $\mathbf{9 7 . 1 4}$ & 5.78 & $\mathbf{9 5 . 1}$ & 7.5 & 2.04 & 0.1801 & NS \\
\hline Wits & $\mathbf{3 . 7 8}$ & 2.61 & $\mathbf{0 . 6}$ & 1.7 & 3.18 & 0.0643 & NS \\
\hline
\end{tabular}




\section{Comparison of the starting craniofacial morphology of the treatment group (T1) and the control group (t1).}

Of the 23 variable investigated, all 23 showed no statistically different differences

between the treatment group and the control group in starting form morphology at the starting

time point as illustrated in Table 9. This data therefore suggests that the pre-treatment

craniofacial morphology of the treatment group and the control group were similar. 
Table 10. Measurements at $\mathrm{t} 1, \mathrm{t} 2$, and $\mathrm{t} 3$ for the control group.

\begin{tabular}{|c|c|c|c|c|c|c|}
\hline \multirow{2}{*}{ Variable } & \multicolumn{2}{|c|}{ t1 } & \multicolumn{2}{c|}{ t2 } & \multicolumn{2}{c|}{ t3 } \\
\cline { 2 - 7 } & Mean & S.D. & Mean & S.D. & Mean & S.D. \\
\hline Sagittal: & & & & & & \\
\hline Olp-Co & $\mathbf{1 0 . 0}$ & 2.2 & $\mathbf{1 1 . 4}$ & 2.6 & $\mathbf{1 1 . 0}$ & 2.2 \\
\hline Olp-A pt & $\mathbf{7 0 . 3}$ & 4.2 & $\mathbf{7 2 . 9}$ & 4.7 & $\mathbf{7 5 . 4}$ & 5.0 \\
\hline Olp-Ms & $\mathbf{4 9 . 2}$ & 3.8 & $\mathbf{5 3 . 4}$ & 4.8 & $\mathbf{5 5 . 6}$ & 4.7 \\
\hline Olp-Mi & $\mathbf{4 9 . 0}$ & 4.3 & $\mathbf{5 3 . 4}$ & 5.1 & $\mathbf{5 5 . 9}$ & 4.8 \\
\hline Olp-Is & $\mathbf{7 7 . 2}$ & 5.5 & $\mathbf{8 0 . 6}$ & 5.7 & $\mathbf{8 2 . 8}$ & 6.0 \\
\hline Olp-li & $\mathbf{7 1 . 9}$ & 4.8 & $\mathbf{7 5 . 4}$ & 5.4 & $\mathbf{7 7 . 5}$ & 5.7 \\
\hline Olp-Pg & $\mathbf{7 3 . 9}$ & 4.8 & $\mathbf{7 7 . 9}$ & 5.2 & $\mathbf{8 0 . 5}$ & 5.1 \\
\hline Vertical: & & & & & & \\
\hline OLs-Apt & $\mathbf{2 6 . 9}$ & 2.2 & $\mathbf{2 8 . 6}$ & 2.0 & $\mathbf{3 0 . 0}$ & 1.9 \\
\hline ANS-Me & $\mathbf{5 9 . 0}$ & 5.1 & $\mathbf{6 2 . 3}$ & 5.7 & $\mathbf{6 3 . 7}$ & 5.8 \\
\hline Is-NL & $\mathbf{2 6 . 0}$ & 2.6 & $\mathbf{2 7 . 2}$ & 2.4 & $\mathbf{2 7 . 6}$ & 2.4 \\
\hline Ii-ML & $\mathbf{3 5 . 4}$ & 3.3 & $\mathbf{3 7 . 3}$ & 3.4 & $\mathbf{3 8 . 6}$ & 3.8 \\
\hline Overbite & $\mathbf{3 . 1}$ & 1.4 & $\mathbf{3 . 1}$ & 1.3 & $\mathbf{3 . 3}$ & 1.1 \\
\hline Msc-NL & $\mathbf{1 8 . 5}$ & 2.0 & $\mathbf{2 0 . 5}$ & 2.3 & $\mathbf{2 1 . 5}$ & 2.4 \\
\hline Mic-ML & $\mathbf{2 7 . 0}$ & 2.4 & $\mathbf{2 8 . 3}$ & 2.5 & $\mathbf{2 9 . 6}$ & 2.9 \\
\hline Angular: & & & & & & \\
\hline SNA & $\mathbf{8 0 . 1}$ & 2.8 & $\mathbf{8 0 . 7}$ & 3.0 & $\mathbf{8 1 . 7}$ & 3.0 \\
\hline SNB & $\mathbf{7 5 . 8}$ & 2.9 & $\mathbf{7 6 . 6}$ & 3.1 & $\mathbf{7 7 . 2}$ & 3.1 \\
\hline ANB & $\mathbf{4 . 3}$ & 1.3 & $\mathbf{4 . 1}$ & 1.6 & $\mathbf{4 . 5}$ & 1.6 \\
\hline SNL-NL & $\mathbf{6 . 4}$ & 2.9 & $\mathbf{6 . 0}$ & 2.8 & $\mathbf{6 . 6}$ & 3.4 \\
\hline SNL-ML & $\mathbf{3 3 . 4}$ & 4.8 & $\mathbf{3 2 . 8}$ & 5.2 & $\mathbf{3 2 . 8}$ & 5.5 \\
\hline SNL-OLs & $\mathbf{1 9 . 9}$ & 3.1 & $\mathbf{1 8 . 9}$ & 3.3 & $\mathbf{1 8 . 0}$ & 4.0 \\
\hline Is/NL & $\mathbf{1 1 0 . 0}$ & 5.0 & $\mathbf{1 0 9 . 9}$ & 6.1 & $\mathbf{1 1 0 . 0}$ & 5.2 \\
\hline li/ML & $\mathbf{9 5 . 1}$ & 7.5 & $\mathbf{9 5 . 5}$ & 5.0 & $\mathbf{9 4 . 6}$ & 4.8 \\
\hline Wits & $\mathbf{0 . 6}$ & 1.7 & $\mathbf{0 . 3}$ & 1.9 & $\mathbf{1 . 1}$ & 2.0 \\
\hline
\end{tabular}


Table 11. Changes in $t 1, t 2$, and $t 3$ for the control group.

\begin{tabular}{|c|c|c|c|c|}
\hline \multirow[b]{2}{*}{ Variable } & \multicolumn{2}{|c|}{ t2-t1 } & \multicolumn{2}{|c|}{ t3-t1 } \\
\hline & $\begin{array}{c}\text { Mean } \\
\text { Difference }\end{array}$ & S.D. & $\begin{array}{c}\text { Mean } \\
\text { Difference }\end{array}$ & S.D. \\
\hline \multicolumn{5}{|l|}{ Sagittal: } \\
\hline Olp-Co & 0.83 & 1.00 & 0.77 & 2.02 \\
\hline Olp-A pt & 1.55 & 1.01 & 3.92 & 2.07 \\
\hline Olp-Ms & 2.53 & 1.03 & 4.92 & 2.06 \\
\hline Olp-Mi & 2.62 & 0.98 & 5.31 & 1.99 \\
\hline Olp-Is & 2.02 & 0.90 & 4.31 & 1.84 \\
\hline Olp-Ii & 2.08 & 0.86 & 4.31 & 1.76 \\
\hline Olp-Pg & 2.38 & 0.81 & 4.62 & 1.64 \\
\hline \multicolumn{5}{|l|}{ Vertical: } \\
\hline OLs-Apt & 1.01 & 0.67 & 2.38 & 1.34 \\
\hline ANS-Me & 1.96 & 0.67 & 3.62 & 1.33 \\
\hline IS-NL & 0.71 & 0.54 & 1.23 & 1.12 \\
\hline Ii-ML & 1.13 & 0.54 & 2.46 & 1.15 \\
\hline Overbite & 0.00 & 0.49 & 0.15 & 1.05 \\
\hline Msc-NL & 1.19 & 0.51 & 2.31 & 1.09 \\
\hline Mic-ML & 0.77 & 0.40 & 2.00 & 0.95 \\
\hline \multicolumn{5}{|l|}{ Angular: } \\
\hline SNA & 0.36 & 0.34 & 1.23 & 0.78 \\
\hline SNB & 0.48 & 0.33 & 1.08 & 0.70 \\
\hline ANB & -0.12 & 0.27 & 0.15 & 0.58 \\
\hline SNL-NL & -0.24 & 0.29 & 0.15 & 0.60 \\
\hline SNL-ML & -0.36 & 0.32 & -0.46 & 0.62 \\
\hline SNL-OLS & -0.60 & 0.33 & -1.46 & 0.69 \\
\hline Is/NL & -0.06 & 0.20 & 0.00 & 0.37 \\
\hline $\mathrm{Ii} / \mathrm{ML}$ & 0.24 & 0.23 & -0.38 & 0.44 \\
\hline Wits & -0.18 & 0.25 & 0.38 & 0.54 \\
\hline
\end{tabular}




\section{Components of molar relationship and overjet change (t2-t1)}

\begin{tabular}{|cccc|}
\hline Overiet Change: & & Molar relationship: & \\
Skeletal Contribution: & & Skeletal Contribution: & \\
1) Maxilla & 1.6 & 1) Maxilla & 1.6 \\
2) Mandible & 2.4 & 2) Mandible & 2.4 \\
Dental Contribution: & & Dental Contribution: & \\
3) Mx incisor & .4 & 3) Mx molar & .9 \\
4) Md incisor & -.3 & 4) Md molar & .2 \\
\hline
\end{tabular}

$$
\text { Overjet Change }=\text { Maxilla }+ \text { Mx incisor }- \text { Mandible }- \text { Md incisor }
$$

Overjet Change $=1.6+(.4)-2.4-(-.3)=-.1 \mathrm{~mm}$

$$
\text { Molar Relationship Change }=\text { Maxilla }+ \text { Mx molar }- \text { Mandible }- \text { Md molar }
$$

Molar Relationship Change $=1.6+(.9)-2.4-(-.2)=-.1 \mathrm{~mm}$

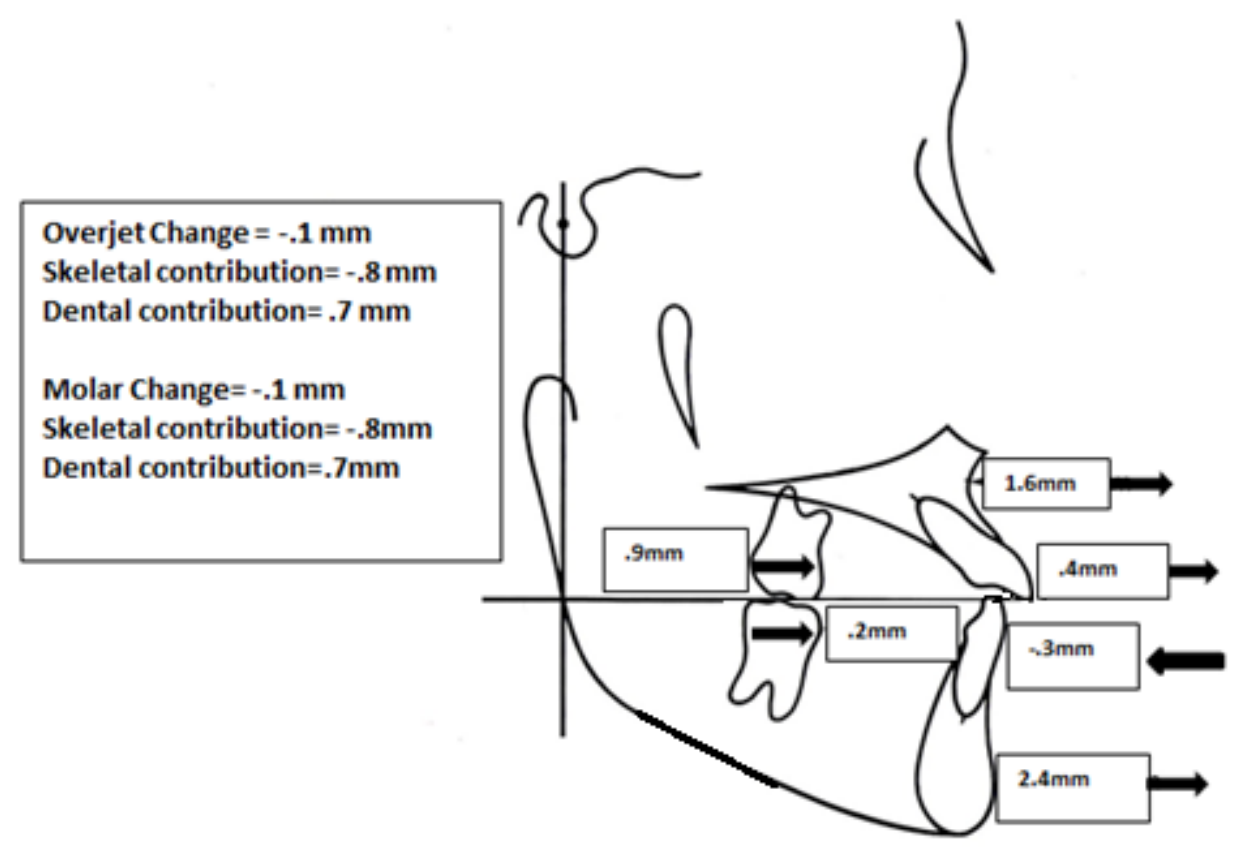

Figure 5. Components of molar relationship and overjet change between $\mathrm{t} 1$ and $\mathrm{t} 2$ for the control group. 


\section{Components of molar relationship and overjet change (t3-t1)}

\begin{tabular}{|cccc|}
\hline $\begin{array}{c}\text { Overjet Change: } \\
\text { Skeletal Contribution: }\end{array}$ & & $\frac{\text { Molar relationship: }}{\text { Skeletal Contribution: }}$ & \\
1) Maxilla & 3.9 & 1) Maxilla & 3.9 \\
2) Mandible & 4.6 & 2) Mandible & 4.6 \\
$\begin{array}{c}\text { Dental Contribution: } \\
\text { 3) Mx incisor }\end{array}$ & .4 & Dental Contribution: & \\
4) Md incisor & -.3 & 3) Mx molar & 1 \\
& & 4) Md molar & .7 \\
\hline
\end{tabular}

Overjet Change $=$ Maxilla + Mx incisor - Mandible - Md incisor

Overjet Change $=3.9+(.4)-4.6-(-.3)=0 \mathrm{~mm}$

Molar Relationship Change $=$ Maxilla + Mx molar - Mandible - Md molar

Molar Relationship Change $=3.9+(1)-4.6-.7=-0.4 \mathrm{~mm}$

Overjet Change $=0 \mathrm{~mm}$

Skeletal contribution $=-.7 \mathrm{~mm}$

Dental contribution $=1.7 \mathrm{~mm}$

Molar Change $=-.4 \mathrm{~mm}$

Skeletal contribution $=-.7 \mathrm{~mm}$

Dental contribution $=.3 \mathrm{~mm}$



Figure 6. Components of molar relationship and overjet change between $\mathrm{t} 3$ and $\mathrm{t} 1$ for the control group. 


\section{Changes in the control in the control group for (t2-t1) and (t3-t1)}

The changes in the control group for (t2-t1) and (t3-t1) are shown in Tables 10 and 11 and Figures 5 and 6 . In the control group for (t2-t1) the change in overjet was $-.1 \mathrm{~mm}$. The skeletal contribution was $-.8 \mathrm{~mm}$ and the dental contribution was $.7 \mathrm{~mm}$. The change in molar relationship was $-.1 \mathrm{~mm}$. The skeletal contribution was $-.8 \mathrm{~mm}$ and the dental contribution was .7 mm. The maxilla, maxillary molars, and maxillary incisors moved forward. The mandible and mandibular molars moved forward; however the mandibular incisors moved backward (Table 10,11 and Figure 6).

In the control group for ( $\mathrm{t} 3-\mathrm{t} 2)$ the change in overjet was $0 \mathrm{~mm}$. The skeletal contribution was $-.7 \mathrm{~mm}$ and the dental contribution was $1.7 \mathrm{~mm}$. The change in molar relationship was -.4 $\mathrm{mm}$. The skeletal contribution was $-.7 \mathrm{~mm}$ and the dental contribution was $.3 \mathrm{~mm}$. The maxilla, maxillary molars, and maxillary incisors moved forward. The mandible and mandibular molars moved forward; however the mandibular incisors moved backward. 
Table 12.Measurements at $\mathrm{T} 1, \mathrm{~T} 2$, and $\mathrm{T} 3$ for the treatment group.

\begin{tabular}{|c|c|c|c|c|c|c|}
\hline \multirow[b]{2}{*}{ Variable } & \multicolumn{2}{|c|}{ T1 } & \multicolumn{2}{|c|}{$\mathrm{T} 2$} & \multicolumn{2}{|c|}{ T3 } \\
\hline & Mean & S.D. & Mean & S.D. & Mean & S.D. \\
\hline Sagittal: & & & & & & \\
\hline Olp-Co & 9.32 & 2.85 & 9.66 & 3.92 & 11.41 & 3.61 \\
\hline Olp-A pt & 73.59 & 4.72 & 73.93 & 4.94 & 75.46 & 5.12 \\
\hline Olp-Ms & 50.76 & 4.46 & 49.30 & 4.30 & 51.47 & 5.31 \\
\hline Olp-Mi & 50.90 & 4.62 & 56.43 & 5.36 & 57.90 & 5.25 \\
\hline Olp-Is & 81.63 & 5.20 & 79.61 & 5.93 & 81.24 & 6.47 \\
\hline Olp-li & 74.85 & 5.27 & 79.89 & 5.93 & 82.05 & 6.79 \\
\hline Olp-Pg & 74.50 & 6.02 & 78.17 & 6.67 & 80.00 & 8.16 \\
\hline Vertical: & & & & & & \\
\hline OLs-Apt & 30.85 & 3.37 & 33.04 & 3.46 & 35.36 & 3.84 \\
\hline ANS-Me & 57.86 & 4.94 & 60.05 & 4.74 & 62.51 & 4.84 \\
\hline Is-NL & 26.88 & 3.05 & 27.04 & 2.49 & 27.58 & 2.42 \\
\hline Ii-ML & 37.01 & 3.10 & 36.14 & 2.80 & 37.72 & 2.95 \\
\hline Overbite & 4.44 & 1.44 & 1.19 & 1.46 & .80 & .88 \\
\hline Msc-NL & 19.56 & 2.04 & 18.75 & 1.86 & 20.45 & 2.04 \\
\hline Mic-ML & 26.51 & 2.50 & 25.91 & 2.08 & 27.89 & 2.66 \\
\hline Angular: & & & & & & \\
\hline SNA & 82.88 & 4.75 & 82.30 & 4.41 & 83.25 & 4.52 \\
\hline SNB & 77.17 & 3.70 & 81.20 & 3.74 & 80.32 & 3.84 \\
\hline ANB & 5.71 & 2.15 & 1.1 & 1.70 & 2.93 & 1.97 \\
\hline SNL-NL & 6.20 & 3.86 & 8.75 & 4.11 & 7.8 & 4.06 \\
\hline SNL-ML & 29.52 & 4.87 & 28.96 & 5.51 & 28.29 & 5.84 \\
\hline SNL-OLs & 15.69 & 4.14 & 20.16 & 3.92 & 17.49 & 3.99 \\
\hline Is/NL & 112.47 & 9.29 & 106.95 & 6.34 & 108.15 & 6.97 \\
\hline li/ML & 97.14 & 5.78 & 105.96 & 7.94 & 102.38 & 11.64 \\
\hline Wits & 3.78 & 2.61 & -0.61 & 2.12 & 1.46 & 2.16 \\
\hline
\end{tabular}


Table 13. Changes in $\mathrm{T} 1, \mathrm{~T} 2$, and $\mathrm{T} 3$ for the treatment group.

\begin{tabular}{|c|c|c|c|c|c|c|c|c|}
\hline \multirow{2}{*}{ Variable } & \multicolumn{4}{|c|}{ T2-T1 } & \multicolumn{4}{|c|}{ T3-T1 } \\
\cline { 2 - 9 } & Mean & S.D. & P value & Sig & Mean & S.D. & P value & Sig \\
\hline Sagittal: & & & & & & & & \\
\hline Olp-Co & 0.34 & 2.14 & .3907 & NS & 2.09 & 2.43 & .0001 & $* * *$ \\
\hline Olp-A pt & 0.34 & 2.35 & .0037 & $* *$ & 1.87 & 2.87 & .1311 & NS \\
\hline Olp-Ms & -1.46 & 2.50 & .0032 & $* *$ & 0.71 & 3.05 & .0437 & $*$ \\
\hline Olp-Mi & 5.53 & 2.58 & .0001 & $* * *$ & 7.0 & 3.45 & .0001 & $* * *$ \\
\hline Olp-Is & -2.02 & 3.64 & .0021 & $* *$ & -0.39 & 3.84 & .5813 & NS \\
\hline Olp-Ii & 5.04 & 3.75 & .0001 & $* * *$ & 7.2 & 4.47 & .0001 & $* * *$ \\
\hline Olp-Pg & 3.7 & 3.18 & .0001 & $* * *$ & 5.5 & 4.68 & .0069 & $* *$ \\
\hline Vertical: & & & & & & & & \\
\hline OLS-Apt & 2.19 & 1.41 & .0001 & $* * *$ & 4.51 & 2.23 & .0001 & $* * *$ \\
\hline ANS-Me & 2.19 & 6.09 & .3085 & NS & 4.65 & 3.49 & .0001 & $* * *$ \\
\hline Is-NL & 0.16 & 1.46 & .5647 & NS & 0.7 & 2.34 & .1152 & NS \\
\hline Ii-ML & -0.87 & 1.59 & .0055 & $* *$ & 0.71 & 2.17 & .0857 & NS \\
\hline Overbite & -3.25 & 1.35 & .0001 & $* * *$ & -3.64 & 1.50 & .0001 & $* * *$ \\
\hline Msc-NL & -0.81 & 1.14 & .0014 & $* *$ & 0.89 & 1.77 & .0026 & $* *$ \\
\hline Mic-ML & -0.6 & 1.33 & .0022 & $* *$ & 1.38 & 1.84 & .0001 & $* * *$ \\
\hline Angular: & & & & & & & & \\
\hline SNA & -0.58 & 1.67 & .1169 & NS & 0.37 & 2.32 & .1479 & NS \\
\hline SNB & 4.03 & 1.61 & .0022 & $* *$ & 3.15 & 2.09 & .0012 & $* *$ \\
\hline ANB & -4.61 & 1.68 & .0001 & $* * *$ & -2.78 & 1.61 & .0002 & $* * *$ \\
\hline SNL-NL & 2.55 & 2.61 & .0025 & $* *$ & 1.6 & 2.87 & .0466 & $*$ \\
\hline SNL-ML & -0.56 & 2.29 & .1917 & NS & -1.23 & 3.15 & .0401 & $*$ \\
\hline SNL-OLs & 4.47 & 2.87 & .0001 & $* * *$ & 1.8 & 3.65 & .0026 & $* *$ \\
\hline Is/NL & -5.52 & 7.77 & .0019 & $* *$ & -4.32 & 8.18 & .0045 & $* *$ \\
\hline Ii/ML & 8.82 & 5.69 & .0001 & $* * *$ & 5.24 & 9.8 & .0065 & $* *$ \\
\hline Wits & -4.39 & 2.40 & .0001 & $* * *$ & -2.32 & 2.37 & .0048 & $* *$ \\
\hline
\end{tabular}




\section{Comparison of T2-T1 (Treatment effects of the Herbst appliance)}

Tables 12 and 13 show the treatment effect of the Herbst appliance along with growth. 18 out of 23 variables investigated showed statistically significant differences with using the Herbst appliance.

\section{Sagittal Changes}

The sagittal variables that showed statistically significant differences were Olp-A pt, OlpMs, Olp-Mi, Olp-Is, Olp-Ii, and Olp-Pg. The maxilla moved forward $0.34 \mathrm{~mm}$. The maxillary molars and maxillary incisors moved backward $1.46 \mathrm{~mm}$ and $2.02 \mathrm{~mm}$, respectively. The mandible moved forward $3.7 \mathrm{~mm}$. The mandibular molars moved forward $5.5 \mathrm{~mm}$ and the lower incisors moved forward $5 \mathrm{~mm}$.

\section{Vertical Changes}

The vertical variables that showed statistically significant differences were OLs-Apt, IiML, Overbite, Msc-NL, and Mic-ML. The maxilla moved downward $2.2 \mathrm{~mm}$ and the upper molars intruded $.8 \mathrm{~mm}$. The lower molar intruded $.6 \mathrm{~mm}$ and the lower incisors intruded $.9 \mathrm{~mm}$. The overbite decreased by $3.3 \mathrm{~mm}$.

The mandible moved downward $2.2 \mathrm{~mm}$ and the upper incisors extruded $.2 \mathrm{~mm}$ but these variables were not deemed statistically significant.

\section{Angular Changes}

The angular variables that showed statistically significant differences were SNB, ANB,SNL-NL, SNL-OLs, Is/NL, Ii/ML, and Wits. The SNB increased by $4^{\circ}$. The ANB decreased by $4.6^{\circ}$. The palatal plane (SNL-NL) increased by $2.6^{\circ}$ and the occlusal plane (SNL- 
OLs) steeped by $2.5^{\circ}$. The upper incisor retracted $5.5^{\circ}$ and the lower incisor proclined $8.8^{\circ}$. The Wits decreased by 4.4 .

The SNA decreased by $.6^{\circ}$ and the mandibular plane decreased by $.5^{\circ}$ but these changes were not statistically significant.

\section{Comparison of T3-T1 (Net Treatment effects)}

Tables 12 and 13 show the treatment effects of the Herbst appliance and phase II treatment with growth. 17 of the 23 variables investigated showed statistically significant differences.

\section{Sagittal Changes}

The sagittal variables that showed statistically significant differences were Olp-Co, OlpMs, Olp-Mi, Olp-Ii and Olp-Pg. The condylar position changed $2.1 \mathrm{~mm}$. The maxillary molars moved forward $0.71 \mathrm{~mm}$ and the mandibular molars moved forward $7.0 \mathrm{~mm}$. The lower incisors moved forward $7.2 \mathrm{~mm}$ and the position of the mandible moved forward $5.5 \mathrm{~mm}$.

The maxilla moved forward $1.9 \mathrm{~mm}$ and the maxillary incisors backward $.4 \mathrm{~mm}$, but these were not deemed statistically significant.

\section{Vertical Changes}

The vertical variables that showed statistically significant differences were OLs-Apt, ANS-Me, Overbite, Msc-NL and Mic-ML. The maxilla moved downward $4.5 \mathrm{~mm}$ while the mandible moved downward $4.6 \mathrm{~mm}$. The overbite decreased by $3.6 \mathrm{~mm}$. The upper molars extruded $0.9 \mathrm{~mm}$ and the lower molars extruded $1.4 \mathrm{~mm}$.

The upper incisors extruded $.7 \mathrm{~mm}$ and the lower incisors intruded $.7 \mathrm{~mm}$ but these were not deemed statistically significant. 


\section{Angular Changes}

The angular variables that showed statistically significant differences were SNB, ANB,

SN-NL, SNL-ML, SNL-OLs, Ii/ML, and Wits. The SNB increased by $3.2^{\circ}$ and the ANB

decreased by $2.8^{\circ}$. The palatal plane increased by $2.9^{\circ}$ and the mandibular plane (SNL-ML)

flattened by $1.2^{\circ}$. The occlusal plane steepened $1.8^{\circ}$. The upper incisors retroclined $4.3^{\circ}$, the lower incisors proclined $5.2^{\circ}$, and the Wits decreased 2.3.

The SNA changed $.4^{\circ}$ but these changes were not statistically significant. 


\section{Components of molar relationship and overjet correction (T2-T1)}

\begin{tabular}{|cccc|}
\hline Overiet Correction: & & Molar relationship: & \\
Skeletal Contribution: & .3 & Skeletal Contribution: & \\
1) Maxilla & 3.7 & 1) Maxilla & .3 \\
2) Mandible & & 2) Mandible & 3.7 \\
Dental Contribution: & -2.3 & Dental Contribution: & \\
3) Mx incisor & 1.3 & 3) Mx molar & -1.8 \\
4) Md incisor & & 4) Md molar & 1.8 \\
\hline
\end{tabular}

Overjet Correction $=$ Maxilla + Mx incisor - Mandible - Md incisor

Overjet Correction $=.3+(-2.3)-3.7-1.3=-7 \mathrm{~mm}$

Molar Relationship Correction $=$ Maxilla + Mx molar - Mandible - Md molar

Molar Relationship Correction $=.3+(-1.8)-3.7-2.3=-7 \mathrm{~mm}$

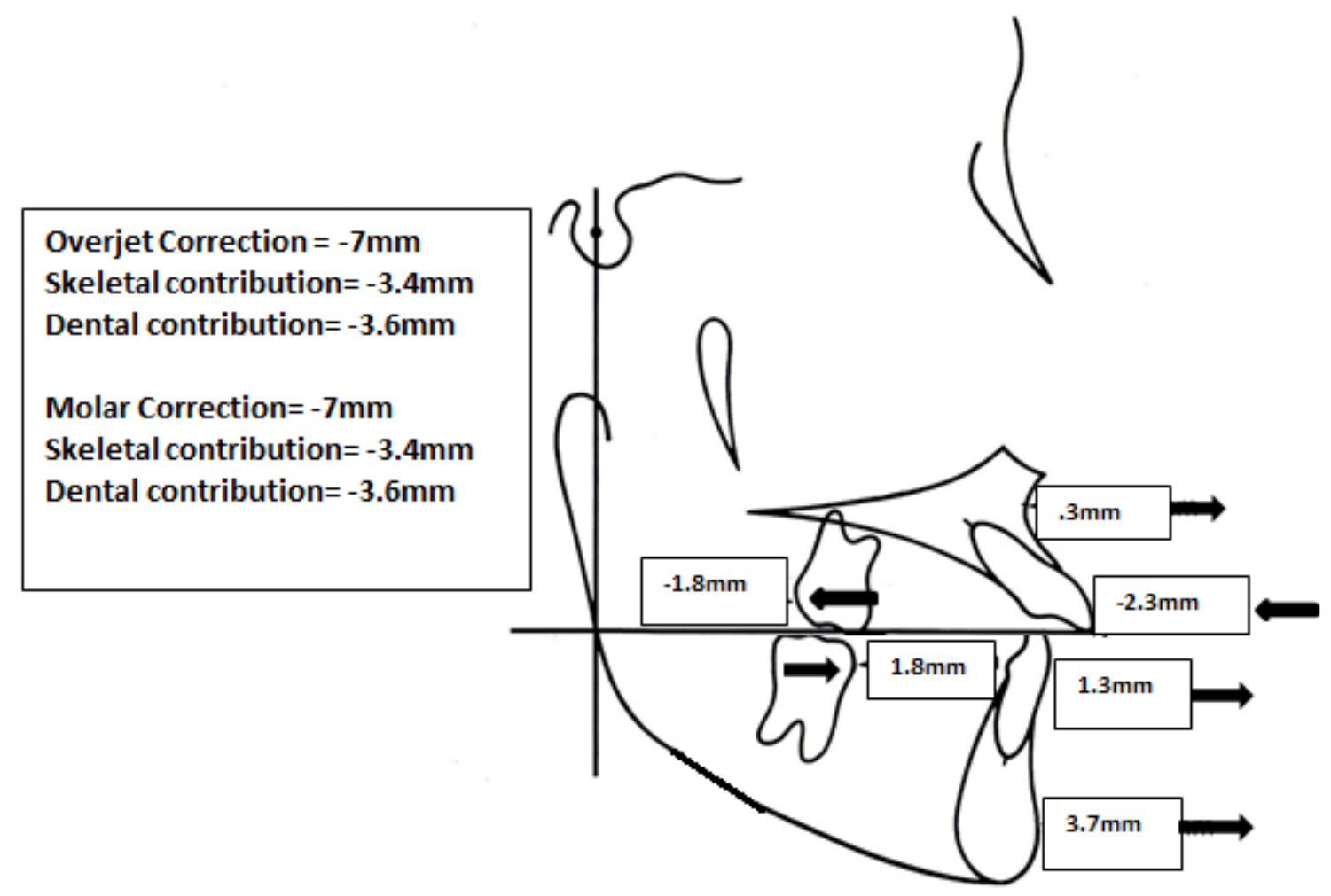

Figure 7. Components of molar relationship and overjet correction between $\mathrm{T} 1$ and $\mathrm{T} 2$ in the treatment group. 


\section{Components of molar relationship and overjet correction (T3-T1)}

\begin{tabular}{|cccc|}
\hline Overjet Correction: & & Molar relationship: & \\
\hline Skeletal Contribution: & & Skeletal Contribution: & \\
1) Maxilla & 1.9 & 1) Maxilla & 1.9 \\
2) Mandible & 5.5 & 2) Mandible & 5.5 \\
$\begin{array}{c}\text { Dental Contribution: } \\
\text { 3) Mx incisor }\end{array}$ & -2.3 & Dental Contribution: & \\
4) Md incisor & 1.7 & 3) Mx molar & -1.2 \\
& & 4) Md molar & 1.5 \\
\hline
\end{tabular}

Overjet Correction $=$ Maxilla + Mx incisor - Mandible - Md incisor

Overjet Correction $=1.9+(-2.3)-5.5-1.7=-7.6 \mathrm{~mm}$

Molar Relationship Correction $=$ Maxilla + Mx molar - Mandible - Md molar

Molar Relationship Correction $=1.9+(-1.2)-5.5-1.5=-6.3 \mathrm{~mm}$

Overjet Correction $=-7.6 \mathrm{~mm}$

Skeletal contribution $=-\mathbf{3 . 6 \mathrm { mm }}$

Dental contribution $=-4 \mathrm{~mm}$

Molar Correction $=-6.3 \mathrm{~mm}$

Skeletal contribution $=-3.6 \mathrm{~mm}$

Dental contribution $=-2.7 \mathrm{~mm}$

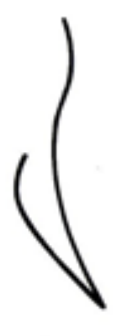

D.



Figure 8. Components of molar relationship and overjet correction (T3-T1) 
Figures 7 and 8 show the changes overjet and molar relationship in the treatment group for (T2$\mathrm{T} 1)$ and (T3-T1). In the treatment group for (T2-T1) the change in overjet was $-7 \mathrm{~mm}$. The skeletal contribution was $-3.4 \mathrm{~mm}$ and the dental contribution was $-3.6 \mathrm{~mm}$. Therefore the overjet correction was $\sim 50 / 50$ skeletal and dental. The change in molar relationship was $-7 \mathrm{~mm}$. The skeletal contribution was $-3.4 \mathrm{~mm}$ and the dental contribution was $-3.6 \mathrm{~mm}$. The molar correction was also $\sim 50 / 50$ skeletal and dental. The maxilla moved forward, however the maxillary molars and maxillary incisors moved backwards. The mandible, mandibular molars, and mandibular incisors moved forward.

In the treatment group for (T3-T1) the change in overjet was $-7.6 \mathrm{~mm}$. The skeletal contribution was $-3.6 \mathrm{~mm}$ and the dental contribution was $-4 \mathrm{~mm}$. Therefore the overjetcorrection was $47 \%$ skeletal and $53 \%$ dental. The change in molar relationship was -6.3 $\mathrm{mm}$. The skeletal contribution was $-3.6 \mathrm{~mm}$ and the dental contribution was $-2.7 \mathrm{~mm}$. The correction was about $57 \%$ skeletal and $43 \%$ dental. The maxilla moved forward. The maxillary molars and maxillary incisors moved backward. The mandible, mandibular molars, and mandibular incisors moved forward. 
Table 14. Changes in $\mathrm{T} 1, \mathrm{~T} 2$, and $\mathrm{T} 3$ after subtracting growth.

\begin{tabular}{|c|c|c|c|c|c|c|c|c|}
\hline \multirow[b]{2}{*}{ Variable } & \multicolumn{4}{|c|}{$(T 2-T 1)-(t 2-t 1)$} & \multicolumn{4}{|c|}{$(T 3-T 1)-(t 3-t 1)$} \\
\hline & Mean & S.D. & P value & Sig & Mean & S.D & P value & Sig \\
\hline \multicolumn{9}{|l|}{ Sagittal: } \\
\hline Olp-Co & -0.26 & 2.14 & .0514 & NS & 1.01 & 2.4 & .0197 & $*$ \\
\hline Olp-A pt & -1.21 & 2.35 & .0006 & $* * *$ & -0.37 & 2.8 & .0001 & $* * *$ \\
\hline Olp-Ms & -3.99 & 2.05 & .0001 & $* * *$ & -2.34 & 3.0 & .0001 & $* * *$ \\
\hline Olp-Mi & 3.52 & 2.58 & .0023 & $* *$ & 2.7 & 3.4 & .0007 & $* * *$ \\
\hline Olp-Is & -4.04 & 3.64 & .0001 & $* * *$ & -1.50 & 3.8 & .0001 & $* * *$ \\
\hline Olp-li & 3.23 & 3.75 & .0031 & $\neq *$ & 2.9 & 4.4 & .0001 & $* \neq *$ \\
\hline Olp-Pg & 1.30 & 3.18 & .0033 & $* *$ & 0.90 & 4.6 & .0001 & $* * *$ \\
\hline \multicolumn{9}{|l|}{ Vertical: } \\
\hline OLs-Apt & 1.18 & 1.41 & .0465 & $* *$ & 1.04 & 2.2 & .0017 & $* *$ \\
\hline ANS-Me & 0.23 & 1.57 & .0654 & NS & 1.07 & 3.4 & .9310 & NS \\
\hline Is-NL & 0.08 & 1.46 & .1452 & NS & 0.13 & 2.1 & .2181 & NS \\
\hline li-ML & -2.0 & 1.59 & .0001 & $\neq * *$ & 0.12 & 2.1 & .0652 & NS \\
\hline Overbite & -3.25 & 1.35 & .0001 & $* * *$ & -4.21 & 1.5 & .0001 & $* * *$ \\
\hline Msc-NL & -0.98 & 1.14 & .0001 & $* * *$ & 0.29 & 1.7 & .0020 & $* *$ \\
\hline Mic-ML & -1.06 & 1.33 & .0001 & $\neq * *$ & 0.78 & 1.8 & .0284 & * \\
\hline \multicolumn{9}{|l|}{ Angular: } \\
\hline SNA & -0.97 & 1.67 & .0012 & $* *$ & -0.18 & 2.3 & .0001 & $* * *$ \\
\hline SNB & 3.55 & 1.61 & .0045 & $* *$ & 2.62 & 2.0 & .0004 & $\neq * *$ \\
\hline ANB & -4.49 & 1.68 & .0003 & $* * *$ & -3.31 & 1.6 & .0001 & $* * *$ \\
\hline SNL-NL & 2.79 & 2.61 & .0562 & NS & 1.05 & 2.8 & .0596 & NS \\
\hline SNL-ML & 0.49 & 2.29 & .9246 & NS & -1.77 & 3.1 & .2777 & NS \\
\hline SNL-OLS & 5.07 & 2.87 & .0001 & $* * *$ & 1.22 & 3.6 & .0016 & $* *$ \\
\hline $\mathrm{Is} / \mathrm{NL}$ & -5.46 & 7.77 & .0001 & $* * *$ & -4.94 & 8.1 & .1315 & $* * *$ \\
\hline $\mathrm{li} / \mathrm{ML}$ & 8.58 & 5.69 & .0001 & $* * *$ & 4.51 & 9.8 & .0032 & $* \neq *$ \\
\hline Wits & -4.21 & 2.40 & .0001 & $* * *$ & -3.19 & 2.3 & .0002 & $* * *$ \\
\hline
\end{tabular}




\section{Comparison of (T2-T1)-(t2-t1) (Treatment effects of the Herbst appliance minus growth)}

Table 14 shows the appliance effects with the Herbst appliance after subtracting growth from treatment changes. 17 out of 23 variables were found to show statistically significant changes after treatment with the Herbst appliance.

\section{Sagittal Changes}

All sagittal variables showed statistically significant differences except Olp-Co. After subtracting growth, the appliance was found to move the maxilla backward $1.2 \mathrm{~mm}$, and the mandible forward $1.3 \mathrm{~mm}$. The maxillary molars were found to move backward $4 \mathrm{~mm}$ and the mandibular molars moved forward $3.5 \mathrm{~mm}$. The maxillary incisors was moved backward $4 \mathrm{~mm}$ and the mandibular incisors moved forward $3.2 \mathrm{~mm}$.

\section{Vertical Changes}

The vertical variables that showed statistically significant differences were OLs-A pt, IiML, Overbite, Msc-NL, and Mic-ML. The appliance was found to move the maxilla downward $1.1 \mathrm{~mm}$. The lower incisors intruded $2 \mathrm{~mm}$. The overbite decreased by $3.3 \mathrm{~mm}$. The upper molar intruded $1 \mathrm{~mm}$ and the lower molars intruded $1.1 \mathrm{~mm}$.

The mandible moved downward $.2 \mathrm{~mm}$ and the upper incisors extruded $.1 \mathrm{~mm}$, but these findings were not deemed statistically significant.

\section{Angular Changes}

All angular variables showed statistically significant differences except SNL-NL and SNL-ML. The SNA decreased $1^{\circ}$, SNB increased $3.6^{\circ}$, and ANB decreased $4.5^{\circ}$. The occlusal plane (SNL-OLs) steepened by $5^{\circ}$. The upper incisors retracted $5.5^{\circ}$ and the lower incisor proclined $8.6^{\circ}$. The wits decreased 4.2 . 
The palatal plane (SNL-NL) steepened by $2.8^{\circ}$ and the mandibular plane steepened by $.5^{\circ}$, but these changes were not statistically significant.

\section{Comparison of (T3-T1)-(t3-t1) (Net treatment effects minus growth)}

Table 14 shows the changes with the Herbst appliance and phase II orthodontic treatment after subtracting growth. 18 of the 23 variables were found to have significant changes after treatment with the Herbst appliance and phase II orthodontic treatment.

\section{Sagittal Changes}

All sagittal variables showed statistically significant differences. The maxilla moved backward $.4 \mathrm{~mm}$. The mandible moved forward $.9 \mathrm{~mm}$. The condylar position changed $1 \mathrm{~mm}$. The maxillary molars and maxillary incisors moved backward $2.3 \mathrm{~mm}$ and $1.5 \mathrm{~mm}$, respectively. The mandibular molars moved forward $2.7 \mathrm{~mm}$ and the lower incisors moved forward $2.9 \mathrm{~mm}$.

\section{Vertical Changes}

The vertical variables that showed statistically significant differences were OLs-Apt, Overbite, Msc-NL, and Mic-ML. The maxilla moved downward $1 \mathrm{~mm}$. The overbite decreased by $4.2 \mathrm{~mm}$. The upper molars intruded $.3 \mathrm{~mm}$ and the lower molar intruded $.8 \mathrm{~mm}$.

The mandible moved downward $1 \mathrm{~mm}$. The upper incisors extruded $.1 \mathrm{~mm}$ and the lower incisors extruded $.1 \mathrm{~mm}$, but these variables were not deemed statistically significant.

\section{Angular Changes}

All angular variables showed statistically significant differences except SNL-NL and SNL-ML. The SNA decreased $.2^{\circ}$, SNB increased $2.6^{\circ}$, and ANB decreased $3.3^{\circ}$. The occlusal plane (SNL-OLs) steepened by $1.2^{\circ}$. The upper incisor retracted $5^{\circ}$ and the lower incisor proclined $4.5^{\circ}$. The Wits decreased by 3.2 . 
The palatal plane (SNL-NL) increased by $1^{\circ}$ and the mandibular plane (SNL-ML) flattened by $1.8^{\circ}$, but these changes were not statistically significant. 


\section{Components of molar relationship and overjet correction (T2-T1) - (t2-t1)}

\begin{tabular}{|cccc|}
\hline Overiet Correction: & & Molar relationship: & \\
\hline Skeletal Contribution: & & Skeletal Contribution: & \\
1) Maxilla & -1.2 & 1) Maxilla & -1.2 \\
2) Mandible & 1.3 & 2) Mandible & 1.3 \\
Dental Contribution: & & Dental Contribution: & \\
3) Mx incisor & -2.8 & 3) Mx molar & -2.8 \\
4) Md incisor & 1.9 & 4) Md molar & 2.2 \\
\hline
\end{tabular}

Overjet Correction $=$ Maxilla + Mx incisor - Mandible - Md incisor

Overjet Correction $=-1.2+(-2.8)-(1.3)-1.9=-7.2 \mathrm{~mm}$

Molar Relationship Correction $=$ Maxilla + Mx molar - Mandible - Md molar

Molar Relationship Correction $=-1.2+(-2.8)-(1.3)-2.2=-7.5 \mathrm{~mm}$

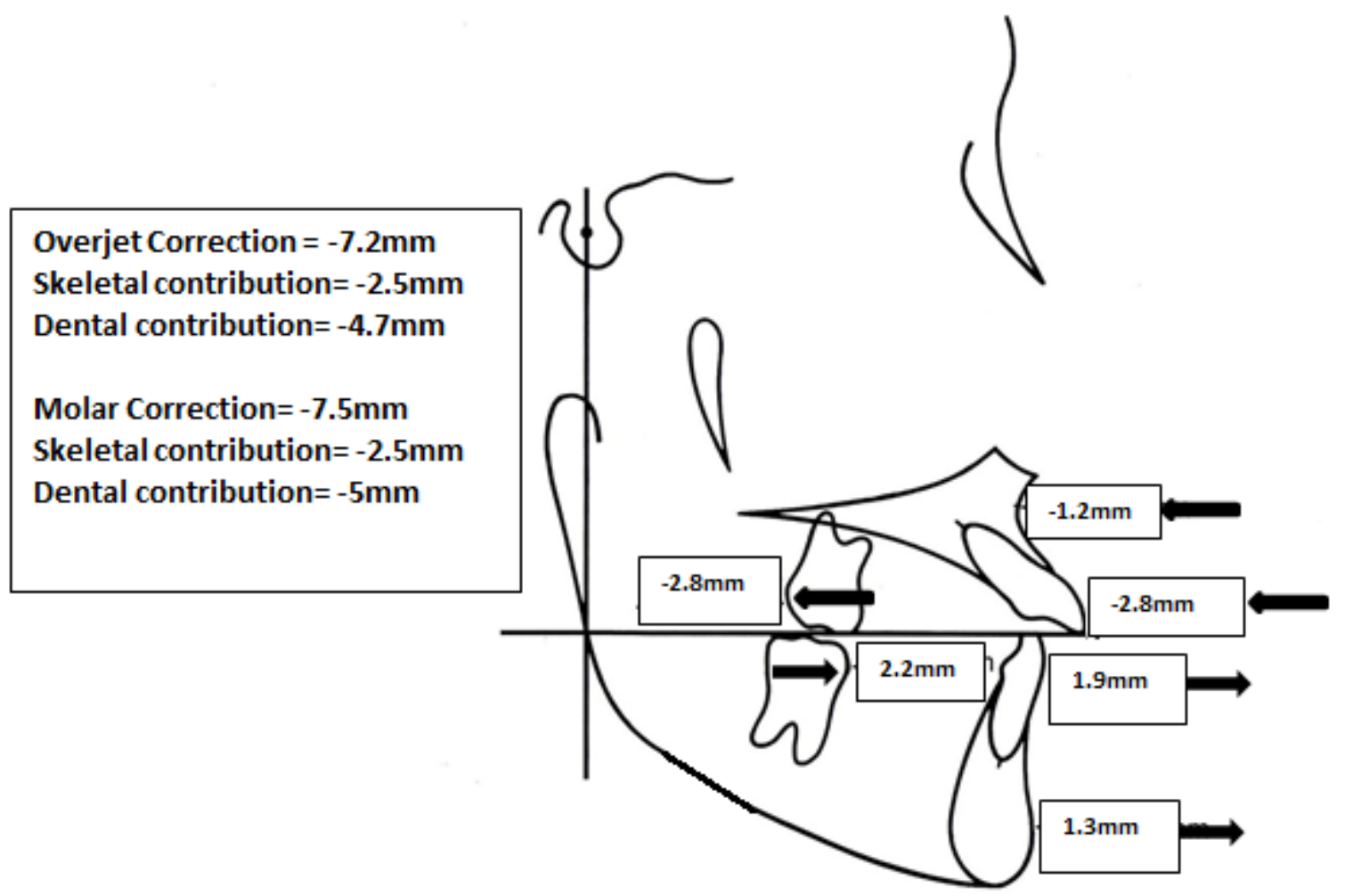

Figure 9. Components of molar relationship and overjet correction between $\mathrm{T} 1$ and $\mathrm{T} 2$ after subtracting growth changes ( $\mathrm{t} 2-\mathrm{t} 1)$. 


\section{Components of molar relationship and overjet correction (T3-T1) - (t3-t1)}

\begin{tabular}{|cccc|}
\hline Overiet Correction: & & Molar relationship: & \\
Skeletal Contribution: & & Skeletal Contribution: & \\
1) Maxilla & -.4 & 1) Maxilla & -.4 \\
2) Mandible & .9 & 2) Mandible & .9 \\
Dental Contribution: & & Dental Contribution: & \\
3) Mx incisor & -1.1 & 3) Mx molar & -1.9 \\
4) Md incisor & 2 & 4) Md molar & 1.8 \\
\hline
\end{tabular}

$$
\text { Overjet Correction }=\text { Maxilla }+ \text { Mx incisor }- \text { Mandible }- \text { Md incisor }
$$

Overjet Correction $=(-.4)+(-1.1)-(.9)-(2)=-4.4 \mathrm{~mm}$

Molar Relationship Correction = Maxilla + Mx molar - Mandible - Md molar

Molar Relationship Correction $=(-.4)+(-1.9)-(.9)-(1.8)=-5.0 \mathrm{~mm}$

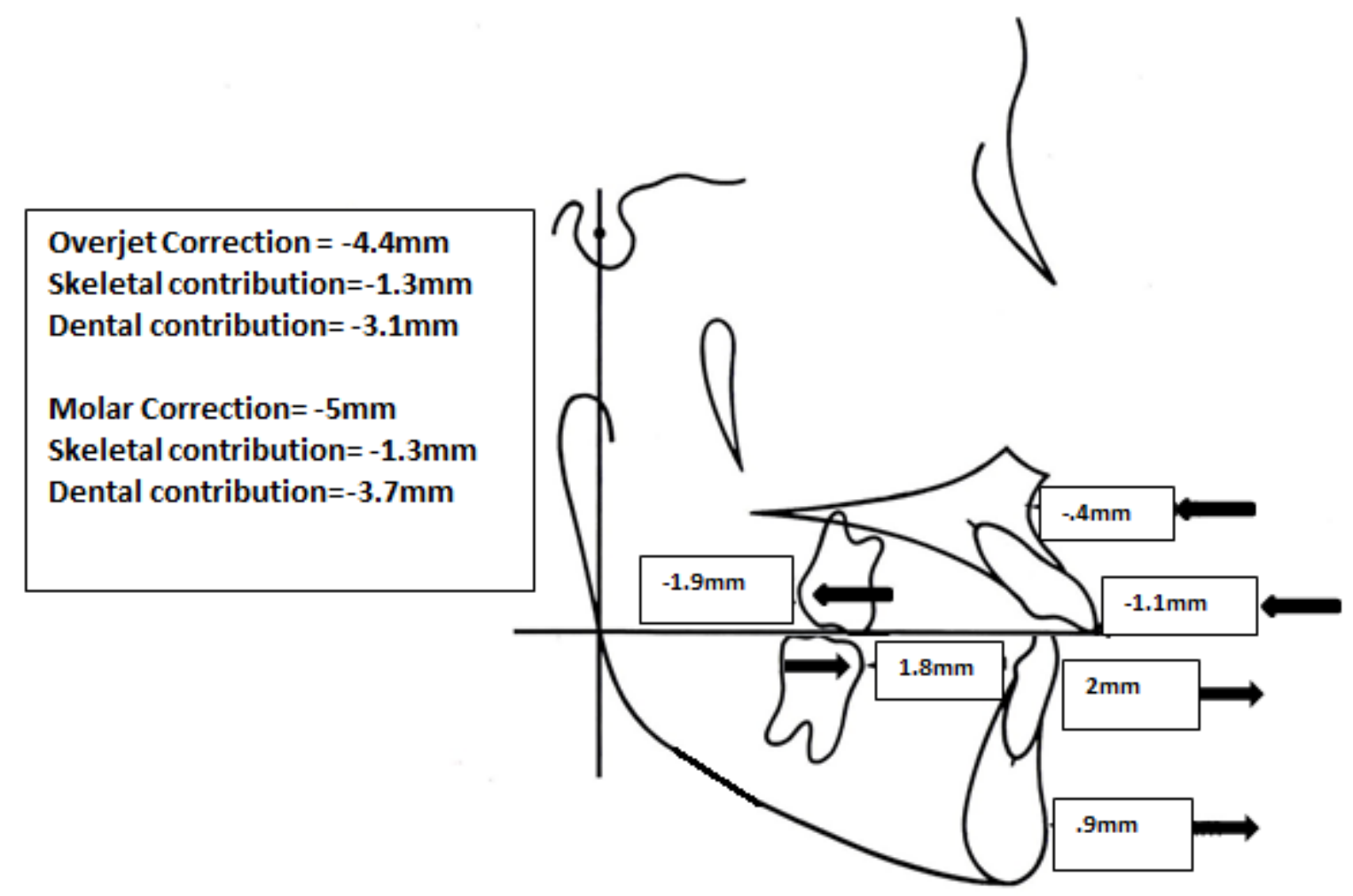

Figure 10. Components of molar relationship and overjet correction between $\mathrm{T} 1$ and $\mathrm{T} 3$ after subtracting growth changes ( $\mathrm{t} 3-\mathrm{t} 1)$. 
Figures 9 and 10 show the changes overjet and molar relationship in the treatment group for (T2-T1)-(t2-t1) and (T3-T1)-(t3-t1). In the treatment group for (T2-T1)-(t2-t1) the change in overjet was $-7.2 \mathrm{~mm}$. The skeletal contribution was $-2.5 \mathrm{~mm}$ and the dental contribution was -4.7 $\mathrm{mm}$. The overjet correction was about $35 \%$ skeletal and $76 \%$ dental. The change in molar relationship was $-7.5 \mathrm{~mm}$. The skeletal contribution was $-2.5 \mathrm{~mm}$ and the dental contribution was $-5 \mathrm{~mm}$. The molar correction was about $33 \%$ skeletal and $67 \%$ dental. The maxilla, maxillary molars and maxillary incisors moved backwards. The mandible, mandibular molars, and mandibular incisors moved forward.

In the treatment group for (T3-T1)-(t3-t1) the change in overjet was $-4.4 \mathrm{~mm}$. The skeletal contribution was $-1.3 \mathrm{~mm}$ and the dental contribution was $-3.1 \mathrm{~mm}$. The overjet correction was about $30 \%$ skeletal and $70 \%$ dental. The change in molar relationship was $-5 \mathrm{~mm}$. The skeletal contribution was $-1.3 \mathrm{~mm}$ and the dental contribution was $-3.7 \mathrm{~mm}$. The molar correction was $26 \%$ skeletal and $74 \%$ dental. The maxilla, the maxillary molars, and maxillary incisors moved backward. The mandible, mandibular molars, and mandibular incisors moved forward. 


\section{CHAPTER V DISCUSSION}

In this study the average age for the treatment group (T1) is 12.34 years. The average time for $\mathrm{T} 1$ to $\mathrm{T} 2$ was about 1.5 years. This is the time that the Herbst appliance was in effect. This time is significantly longer than most clinicians use the Herbst appliance. The time from T2-T3 was about 1.8 years. This is referred to as the phase II treatment period but there may also be a small period of observation immediately following the removal of the Herbst appliance.

The objective of this study is to determine the amount of skeletal and dental changes of Class II adolescent patients treated with the reinforced banded Herbst appliance. The results of this research should provide additional information on appropriate placement time when using the Herbst appliance and the length of treatment required by the Herbst appliance. Cephalometric measurements were performed on radiographs and dental cast measurements were taken before any phase of treatment (T1), immediately after Herbst removal (T2), and immediately following phase II orthodontic treatment (T3). Measurements were compared to a matched control sample of untreated Class II patients from the Bolton-Brush study.

In order to interpret the results of this study, it is important to evaluate the changes that occurred in both skeletal and dental components in the sagittal, the vertical, and the angular directions. In this study 22 variables were used to describe the changes in position of the maxillary skeletal base, the mandibular skeletal base, the maxillary molars and incisors, the mandibular molars and incisors, and the condyle. 


\section{Sagittal Changes (Skeletal)}

During the Herbst appliance treatment period (T2-T1) the growth of the maxilla was halted while the growth of the mandible was accelerated. In the control group (t2-t1) during this same period the maxilla and mandible both moved forward with the maxilla moving forward more. This indicates that growth of the maxilla of the treatment group was slowed while growth of the mandible was accelerated during this period when compared to the control. This was consistent with previous studies in which the maxillary base moved forward 0.1-1.2 mm during treatment, ${ }^{4,7,51,63,83-91}$ which was found to be $0.2-1.2 \mathrm{~mm}$ less than the forward movement observed in the control group ${ }^{4,63,60}$. In some studies, A-point moved backwards 0.5-1.0 mm

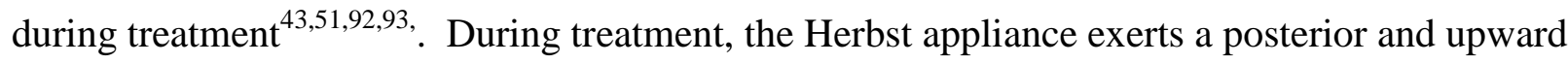
force on the maxilla and the maxillary dentition similar to a high-pull headgear ${ }^{4,66,78,94,95}$. The Herbst appliance effect is found by subtracting growth (control group) from the treatment group (T2-T1)-(t2-t1). The net effect was the maxilla moved backward and the mandible moved forward due to the appliance alone (Table 11,13, and 14).

The total treatment effect which includes the time of treatment when the Herbst appliance was used and during phase II treatment after it is removed (T3-T1), the maxilla and mandible moved forward however the mandible moved forward significantly more than the maxilla. This was consistent with that shown in previous studies where the maxillary base moved forward 0.8 $1.4 \mathrm{~mm}^{7,77,87,92}$ in the short-term and $1.3-5.1 \mathrm{~mm}^{63,64,78,87,96,97}$ in the long-term post-treatment period. In the control group (t3-t1) during this same period the maxilla and mandible moved forward about the same amount. The total treatment effect of Herbst and phase II appliance is found by subtracting the control growth (T3-T1)-(t3-t1). Once growth is subtracted there is a net backward on the maxilla and net forward movement on the mandible. The mandible moved 
forward more than the maxilla when compared to the control group. These results indicate that in the treatment group the maxilla was significantly restrained and the mandible moved significantly more forward than the control group. This is consistent with previous studies that have shown forward movement of the mandibular jaw base (as measured by Pg-point) of 0.9-5.0 $\mathrm{mm}$ in response to treatment ${ }^{51,63,67,77,83,85-92,98-101}$. (Table 11,13, and 14)

\section{Sagittal Changes (Dental)}

During the time of treatment when the Herbst appliance was used (T2-T1) the maxillary molars and maxillary incisors moved backward while the mandibular molars and mandibular incisors moved forward. In the control group (t2-t1) during this same period the maxillary molars, maxillary incisors, and the mandibular molars moved forward while the mandibular incisors moved backward. The Herbst appliance effect is found by subtracting growth (control group) from the treatment group (T2-T1)-(t2-t1). The Herbst caused the maxillary molars and incisors to move backward and mandibular molars and incisors to move forward. This is consistent with the amount of distal molar movement in response to Herbst treatment reported in other studies of 0.6-3.0 mm $\mathrm{mm}^{4,63,67,77,78,85,89,90,92,94,98,99}$. The amount of lower molar forward movement falls within the range of mandibular molar movement reported in previous studies of $0.9-5.5 \mathrm{~mm}^{4,7,57,67,77,83-86,88-90,98-100}$. (Table 11,13, and 14)

The total treatment effect of the Herbst appliance and phase II treatment (T3-T1) the maxillary molar did move slightly forward but the maxillary incisors moved backward. The mandibular molars and incisors did move significantly forward. In the control group (t3-t1) during this same period the maxillary molars, maxillary incisors, mandibular molars, and incisors moved forward. The total treatment effects of the Herbst appliance and phase II treatment with 
no growth (T3-T1)-(t3-t1) shows significant maxillary molar and maxillary incisor backward movement. There is also significant mandibular molar and mandibular incisor forward movement. This is consistent with studies that have shown the Herbst appliance exerts a posterior superior force on the maxillary dentition and an anterior inferior force on the mandibular dentition ${ }^{9,20,65,85,88,98}$, which generally results in distalization of the maxillary molars, retroclination of the maxillary incisors, mesial movement of the mandibular molars, and proclination of the mandibular incisors ${ }^{65,70,71,99,100}$. (Table 11,13, and 14)

\section{Overjet Correction}

The amount of skeletal and dental contribution to the overjet change in the treatment group was calculated using the formulas in Table 2 . There was a large amount of overjet change in the treatment group while using the Herbst appliance (T2-T1). Dental correction account for about twice as much as skeletal correction. The control group during this time (t2-t1) had relatively no overjet change. The Herbst appliance effect is found by subtracting the control growth (T2-T1)-(t2-t1). The appliance caused a large change in overjet but the dental contribution was more than the skeletal. In previous studies, overjet reductions ranging from 3.39.8 mm after Herbst treatment have been reported ${ }^{4,7,9,43,51,63,65,70,77,85,86,89-91,98-101}$. (Figures 6, 9, and 12)

The total treatment effect of the Herbst appliance and phase II treatment (T3-T1) showed a large amount of net overjet correction. The dental component accounted for substantially more overjet correction. The control group during this time (t3-t1) again had basically no overjet change. The total treatment effect with the Herbst appliance and phase II treatment without growth (T3-T2)-(t3-t2) also displays significant overjet correction. The skeletal and dental 
correction account for about the same amount. (Figures 6,7,9,10,12,13). Some studies have shown the skeletal component accounting for $70-85 \%$ of the overjet correction (WIGAL). Previous studies have found in the overjet of 0.3-2.4 $\mathrm{mm}$ in the long-term post-treatment period $^{63,89,96,97,102}$. In total, studies have found that the Herbst appliance caused an overjet correction between 3.3 and $5.7 \mathrm{~mm}$ from the pre-treatment to the long-term post-treatment period $^{63,89,96,102,104}$. (Figures 8, 11, 14)

\section{Molar Relationship Correction}

The amount of skeletal and dental contribution to the molar relationship change in the treatment group was calculated using the formulas in Table 2. During Herbst appliance wear (T2-T1) there was a tremendous amount of molar relationship correction. Again the dental component accounted for about twice as much correction as the skeletal components. The control group during this time (t2-t1) had basically no change in molar relationship. The effects of the Herbst appliance alone (T2-T1)-(t2-t1) also shows tremendous molar correction. There was still more dental correction than skeletal correction. These results are similar to other studies that have found about a $27 \%$ skelatal and $73 \%$ dental contribution to molar relationship correction following Herbst treatment ${ }^{82}$. In previous studies, molar relationship corrections ranging from 3.0-9.3 mm after Herbst treatment have been reported ${ }^{4,51,63,65,70,77,83,85,88-91,93,98,99}$. (Figures 6, 9, and 12)

The total treatment effect of the Herbst appliance and phase II treatment (T3-T1) accounted for significant correction in the molar relationship. The dental correction accounted for substantially more correction than the skeletal components. The control group during this time (t3-t1) had a slight change in molar relationship. The skeletal component was a little more 
than the dental. The total treatment effect with the Herbst appliance and phase II treatment without growth (T3-T1)-(t3-t1) shows significant molar relationship correction. The dental component still accounted for more of the correction then the skeletal components (Figures $6,7,9,10,12,13)$. The Herbst appliance initially produced a large net molar correction, then relapsed in the short-term post-Herbst period until a relatively stable net molar correction was maintained. As with other studies the molar relationship correction followed the same general trends as the overjet correction. These results are similar to other studies that have found about a $39 \%$ skelatal and $61 \%$ dental contribution to molar relationship correction following Herbst treatment $^{82}$. (Figures 8,11 , and 14)

\section{Vertical Changes (Skeletal)}

During the time of treatment when the Herbst appliance was used (T2-T1) the maxilla and mandible moved downward. The control (t2-t1) showed the maxilla and mandible moved downward. The appliance effect after growth is subtracted (T2-T1)-(t2-t1) also showed that the maxilla and mandible moved downward. There is conflicting information about the vertical changes experienced with Herbst treatment. In this study there was a statistically significant downward movement of the maxilla. The effect of phase II treatment and the Herbst (T3-T1) showed the maxilla and mandible moved downward, however neither were statistically significant. The control (t3-t1) showed the maxilla and mandible moved downward. After growth is subtracted (T3-T1)-(t3-t1) the results were similar, the maxilla and mandible moved downward. There was statistically significant downward movement of the maxilla. Treatment with the Herbst appliance had no statistically significant effect on the anterior lower facial height and increases in this measurement are attributable to normal growth. Previous studies have 
reported increases of $0.4-4.1 \mathrm{~mm}$ in response to Herbst treatment ${ }^{9,51,67,71,84,93,100}$, however Pancherz found that no difference was evident between the treatment and control groups in the 12-month post-treatment period ${ }^{80}$. (Tables 11,13 , and 14)

\section{Vertical Changes (Dental)}

During treatment with the Herbst appliance (T2-T1) the upper molars intruded and the upper incisors extruded. The lower molars and lower incisors also intruded. The overbite decreased. The appliance effect after growth is subtracted (T2-T1)-(t2-t1) still shows slight upper molar intrusion and upper incisor extrusion. The lower molars and lower incisors both intruded. The overbite decreased. During phase II treatment and the Herbst period (T3-T1) all molars and incisors extruded and the overbite decreased significantly. The control group (t3-t1) also showed all molars and incisors extruded but the overbite did not change. With phase II treatment and Herbst treatment without growth (T3-T1)-(t3-t1) all molars and incisors had little to no extrusion. There was significant correction to the overbite. This shows that although the Herbst appliance has an intrusive effect to all molars and the lower incisors this effect was temporary. As mentioned earlier the Herbst appliance exerts a posterior superior force on the maxillary dentition and an anterior inferior force on the mandibular dentition ${ }^{9,65,70,85,88,98,102}$. This is consistent with the reports of maxillary first molar intrusion of $0.5-1.1 \mathrm{~mm}$ in response to Herbst treatment reported in previous studies ${ }^{51,71,78,92,105}$. Previous studies report mandibular incisor intrusion of $0.4-2.4 \mathrm{~mm}$ in response to Herbst treatment ${ }^{51,71,84,92,100,105}$. This study is consistent with other studies that have shown an overbite reduction of 1.9-5.6 mm after Herbst treatment $^{7,9,51,63,91,93,100,102,105}$. (Tables 11, 13, and 14) 


\section{Angular Changes (Skeletal)}

During Herbst appliance treatment (T2-T1) the SNA slightly decreased, the SNB increased, and the ANB decreased, the palatal plane and the occlusal plane steepened. The mandibular plane flattened. For the control group (t2-t1) the SNA and SNB slightly increased, and ANB roughly stayed the same. The palatal, mandibular, and occlusal planes stayed roughly the same. The appliance effect without growth (T2-T1)-(t2-t1) shows the SNA decreased, SNB increased, and ANB decreased. The palatal plane, the occlusal plane, and the mandibular plane steepened. During phase II treatment and Herbst appliance treatment (T3-T1) the SNA slightly increased, the SNB increased, and the ANB decreased, the palatal plane and the occlusal plane steepened. The mandibular plane flattened. For the control group (t3-t1) the SNA, SNB, and ANB all slightly increased. The palatal plane slightly increased, mandibular plane stayed the same, and occlusal planes slightly decreased. The phase II treatment and Herbst appliance effect without growth (T3-T1)-(t3-t1) shows the SNA decreased, SNB increased, and ANB decreased. The palatal plane and the occlusal plane steepened, and the mandibular plane flattened. The change in SNB is slightly higher than previous studies that showed an increase in the SNB angle of 0.3-2.6 $6^{63,89,96,102}$. This was consistent with other studies that reported decreases in the ANB angle from 1.1-3.9 9,63,64,67,70,71,77,87-89,94,95,98,100 in response to Herbst treatment. Some studies have shown that the palatal plane tipped downwards $0.2-1.0^{\circ}$ in response to Herbst treatment ${ }^{9,63,64,67,70,71,77,87-89,94,95,98-100}$. This is also consistent with previous studies that have shown an initial 1.1-5.1 ${ }^{\circ}$ clockwise tipping of the occlusal plane $e^{7,51,67,70,71,77,78,88,89,95,98,99,102}$. There are conflicting views on the effect the Herbst has on the mandibular plane. No significant differences were found in the changes in mandibular plane angle (SNL-ML) in the treatment group relative to the control group in this study. Some investigators have found an increase in 
the mandibular plane angle during Herbst treatment ${ }^{7,9,77,84,87-89,94,95,98,99,102}$, others have found that the mandibular plane angle decreased $0.1-2.0^{\circ}$ during treatment ${ }^{71,84,92,93,96}$, and others have found that it remained unchanged ${ }^{9,63,91}$. In the short-term post-treatment period, some researchers have found that the mandibular plane angle decreased $0.5-0.7^{\circ},{ }^{92,102,103}$, while others have reported that it remained unchanged ${ }^{77}$. In the long-term post-treatment period, Ruf and Pancherz concluded that the Herbst appliance does not have a significant effect on the mandibular plane $\operatorname{angle}^{106}$. (Tables 11, 13, and 14)

\section{Angular Changes (Dental)}

During Herbst appliance treatment (T2-T1), the upper incisors retroclined and the lower incisor proclined, and the Wits decreased. In the control group ( $\mathrm{t} 2-\mathrm{t} 1)$ the upper, lower incisors, and wits roughly stayed the same. The appliance effect without growth (T2-T1)-(t2-t1) shows the upper incisors also retracted and the lower incisor proclined. The wits decreased. During phase II treatment and Herbst appliance treatment (T3-T1), the upper incisors retroclined and the lower incisor proclined and the Wits decreased. In the control group (t3-t1) the upper, lower incisors, and wits roughly stayed the same. The phase II treatment and Herbst appliance effect without growth (T3-T1)-(t3-t1) shows the upper incisors also retracted and the lower incisor proclined, and the wits decreased. The amount of retroclination of the upper incisors is consistent with the reported literature that shows maxillary incisor distal movement of 0.5-3.6 $\mathrm{mm}$ and maxillary incisor retroclination of $3.2-8.2^{\circ}$ in response to Herbst treatment ${ }^{7,63,71,77,83-86,88-93,95-99,102}$. The proclination in this study is also consistent with the reported literature that shows mandibular incisor mesial movement of $0.2-4.0 \mathrm{~mm}$ and mandibular incisor proclination of $5.4-10.8^{\circ}$ in response to Herbst treatment ${ }^{7,9,51,65,67,71,77,83-85,87-90,92,93,95,96,98-100}$. The wits for this study was 
slightly larger than the than the Wits decrease between 2.4 and $3.0 \mathrm{~mm}$ reported in other studies $^{67,77,88,95,103}$. (Tables 11, 13, and 14) 


\section{CHAPTER VI \\ SUMMARY, CONCLUSIONS, RECOMMENDATIONS}

\section{Summary}

The purpose of this study was to determine the amount of skeletal and dental changes of Class II adolescent patients treated with the reinforced banded Herbst appliance. The results of this research should provide additional information on appropriate placement time when using the Herbst appliance and the length of treatment required by the Herbst appliance. Cephalometric measurements were performed on radiographs and dental cast measurements were taken before any phase of treatment (T1), immediately after Herbst removal (T2), and immediately following phase II orthodontic treatment (T3). Measurements were compared to a matched control sample of untreated Class II patients from the Bolton-Brush study. The results of this study provide important information on the effectiveness of treatment with the reinforced banded Herbst appliance and offer new information on the length of time this appliance should be used. This information will thus be useful in determining the most appropriate time and length of treatment required when using the Herbst appliance for treating class II skeletal patterns.

The skeletal and dental difference between the treatment and control subjects for each variable across the three time periods (T1, T2, and T3) were analyzed. The differences between certain time points were analyzed to investigate: $(\mathrm{T} 2-\mathrm{T} 1)=$ the effects of the Herbst appliance plus growth and $(\mathrm{T} 3-\mathrm{T} 1)=$ the net effect of treatment with the Herbst appliance and after it is removed. These time points were also analyzed to investigate the effect without growth: (T2- 
$\mathrm{T} 1)-(\mathrm{t} 2-\mathrm{t} 1)=$ the Herbst appliance effect without growth and $(\mathrm{T} 3-\mathrm{T} 1)-(\mathrm{t} 3-\mathrm{t} 1)=$ the net effect of treatment with the Herbst appliance and after it was removed without growth.

The results of this study were interpreted by evaluating the changes that occurred in both skeletal and dental components in the sagittal, the vertical, and the angular directions. In this study 22 variables were used to describe the changes in position of the maxillary skeletal base, the mandibular skeletal base, the maxillary molars and incisors, the mandibular molars and incisors, and the condyle.

\section{Conclusions}

1) The forward movement of the maxilla was initially restrained during Herbst tx, but normal growth resumed during the phase II tx. The overall net effect after growth was subtracted was a restrictive effect to the maxilla (T2-T1)-(t2-t1) and (T3-T1)-(t3-t1).

2) The mandible was initially moved forward significantly during Herbst tx, however, there was relapse was seen in the phase II period. The overall net effect after growth was subtracted was a protrusive effect to the mandible (T2-T1)-(t2-t1) and (T3-T1)-(t3-t1).

3) The maxillary molars were initially distalized during Herbst Tx, then relapsed in phase II. The overall net effect after growth was subtracted was a more posterior position (T2$\mathrm{T} 1)-(\mathrm{t} 2-\mathrm{t} 1)$ and $(\mathrm{T} 3-\mathrm{T} 1)-(\mathrm{t} 3-\mathrm{t} 1)$.

4) The mandibular molars were initially mesialized during Herbst tx, then some relapse was seen in phase II tx. The overall net effect after growth was subtracted was a more anterior position (T2-T1)-(t2-t1) and (T3-T1)-(t3-t1). 
5) The maxillary incisors moved backward and retroclined after treatment during Herbst tx, then relapsed in phase II tx. The overall net effect after growth was subtracted was a more posterior position (T2-T1)-(t2-t1) and (T3-T1)-(t3-t1).

6) The mandibular incisors moved forward and proclined after treatment from Herbst tx, then relapsed in phase II tx. The overall net effect after growth was subtracted was a more anterior position (T2-T1)-(t2-t1) and (T3-T1)-(t3-t1).

7) A net overjet correction of $-7.0 \mathrm{~mm}$ occurred from Herbst tx, then relapse was seen in phase II tx. The overall net effect after growth was subtracted was -7.2 mm for (T2-T1)-(t2-t1) and $-4.4 \mathrm{~mm}$ for (T3-T1)-(t3-t1).

8) A molar relationship correction of $-7 \mathrm{~mm}$ occurred from Herbst tx, then relapse was seen in phase II tx. The overall net effect after growth was subtracted was -7.5 mm for (T2-T1)(t2-t1) and -5 mm for (T3-T1)-(t3-t1).

9) The SNB increased from Herbst tx, then relapsed in phase II tx. The overall net effect after growth was subtracted was an increase in SNB for (T2-T1)-(t2-t1) and (T3-T1)-(t3-t1).

10) The ANB decreased after treatment from Herbst tx, then relapse was seen in phase II tx. The overall net effect after growth was subtracted was a decrease in ANB for (T2-T1)-(t2-t1) and (T3-T1)-(t3-t1).

11) The palatal plane and occlusal plane had a slight clockwise rotation from Herbst tx, then relapse occurred in phase II tx. The overall net effect after growth was subtracted was a steepening of the planes for (T2-T1)-(t2-t1) and (T3-T1)-(t3-t1). 
12) The wits decreased from Herbst tx, then increased slightly during phase II tx. The overall net effect after growth was subtracted was a decrease in wits for (T2-T1)-(t2-t1) and (T3T1)-(t3-t1).

The Herbst appliance when used for an average of 1.5 years was effective in correcting class II dental and skeletal malocclusions. The Herbst appliance when used for a longer period of time seems to allow for more over correction and less relapse.

\section{Recommendations}

Repeating the study with images from cone beam CT scans would allow more accurate identification of landmarks and more precise visualization of anatomic structures. Analysis of the changes, especially temporomandibular joint changes could be more accurately identified and observed. As these machines become more affordable and common place the access to the information these scans contain will become more prevalent. 


\section{REFERENCES}

1. Andresen, V., and Häupl, K.: Funktions-Kieferorthopädie. H. Meusser. Leipzig, 1936

2. Balters, W.: Die Technik und Übung der allfemeinen und speziellen Bionatortherapie. Quintessenz, 1: 77, 1964.

3. Fränkel, R.: Funktionskeiferorthopädie und der Mundhof als apparative Basis. V.E.B. Verlag Volk \& Gesundheit. Berlin, 1967.

4. Pancherz, H. The Herbst Appliance Editorial Aquarium 1995; Barcelona Spain.

5. Croft, RS, Buschang, PH, English, JD, and Meyer R. A cephalometric and tomographic evaluation of Herbst treatment in the mixed dentition. Am J Orthod Dentofacial Orthop. 1999; 116: 435-443.

6. Woodside, D.G., Metaxas, A, Altuna, G. The influence of functional appliance therapy on glenoid fossa remodeling. Am J Orthod Dentofacial Orthop. 1987; 92: 181-198.

7. Paulsen, H. U., Karle, A, Bakke, M., Heskind, A. CT scanning and radiographic analysis of temperomandibular joints and cephalometric analysis in a case of Herbst treatment in late puberty. Eur J Orthod. 1995; 17: 165-75.

8. Bakke, M., Paulsen, H. U., Herbst treatment in late adolescence: clinical, electromyographic, kenesiographic, and radiographic analysis of one case. Eur J Orthod. 1989; 11: 3997-407.

9. Pancherz, H.: Treatment of Class II malocclusions by jumping the bite with the Herbst appliance. A cephalometric investigation. Am J Orthod. 76: 423-442, 1979.

10. Hanks, Stephen D., et al. "Trying to get out of the 20th century: a partial translation of Emil Herbst's 1910 text." World Journal of Orthodontics 1.1 (2000).

11. Dischinger, TG. Edgewise bioprogressive Herbst appliance. J Clinc. Ortho. 1989; 23: 608-617.

12. Dischinger, TG. Edgewise Herbst Appliance. J Clinc. Ortho. 1995; 29: 738-742.

13. Mayes, J. H. "Improving appliance efficiency with the Cantilever Herbst. A new answer to old problems." Clin Impressions 3.2 (1994): 2-5.

14. Mayes, Joe H. "The Cantilever Bite Jumper (CBJ)." Orthodontic Treatment of the Class II Noncompliant Patient: Current Principles and Techniques (2006): 59. 
15. Corrucini, R.S.: Anthropological aspects of orofacial and occlusal variations and anomalies. In Kelly MA, Larsen CS (editors), Advances in dental anthropology, New York, 1991, Wiley-Liss.

16. Corrucini, R.S., Pacciani, E.: "Orthodontistry" and dental occlusion in Etruscans, Angle Orthod. 59: 61-64, 1989.

17. Kingsley, N.W.: Treatise on oral deformities as a branch of mechanical surgery, New York, 1880, Appleton.

18. Angle, E.H.: Treatment of malocclusion of teeth and fractures of the maxillae, Angle's system, ed. 6, Philadelphia, 1900, SS White Dental Mfg Co.

19. Profitt W.R., Fields, H.W. Contemporary Orthodontics. $3^{\text {rd }}$ ed. Moseby Inc. St. Louis, MO 2000.

20. Henry, R. G. "A classification of Class II, division I malocclusion." The Angle Orthodontist 27.2 (1957): 83-92.

21. Moyers, Robert E., et al. "Differential diagnosis of Class II malocclusions: Part 1. Facial types associated with Class II malocclusions." American journal of orthodontics 78.5 (1980): 477-494.

22. McNamara, JA Jr. Components of Class II Malocclusion in children 8-10 years of age. Angle Orthod. 1981; 51: 177-202.

23. Enlow, D.H. Facial Growth. $3^{\text {rd }}$ ed. WB Saunders Co. 1990.

24. McNamara, James Jr., Brudon, W. Orthodontic and Orthopedic treatment in the Mixed Dentition. Needham Press Inc. Ann Arbor, MI 1993.

25. Bishara SE, Hoppens BJ, Jakobsen JR, et al. Changes in the molar relationship between the deciduous and permanent dentitions: A longitudinal study. Am J Orthod Dentofacial Orthop 1988; 93: 19-28.

26. Ngan, P.W., Byczek, E., Scheik. Longitudinal Evaluation of Growth changes in Class II division subjects. Seminars in Orthod. 3: 4 Dec 1997 pp. 222-231.

27. McLain, J.B., Profitt, W.R. Oral Health Status in the United States: Prevalence of Malocclusion. J Dent Educ. 1985; 49: 386-396.

28. Kelly, J.E., Sanchez, M., Vankirk, L.E. An assessment of the occlusion of the teeth of children. DHEW Publication No. (HRA) 74-1612, Washington, DC: National Center for Health Statistics, 1973. 
29. Kelly, J.E., Harvey, C. An assessment of the teeth of youths 12-17 years, DHEW Publication No. (HRA) 77-1644, Washington, DC: National Center for Health Statistics, 1977.

30. McLain, J.B., Steedle, J.R., Vig, P.S. Face height and dental relationships in 1600 children: A survey. J Dent Res. 1983; 62: 308.

31. McNamara, JA Jr. A method of cephalometric evaluation. Am J Orthod. 1984; 86: 449469.

32. McNamara Jr, J. A., E. W. Brust, and M. L. Riolo. "Soft tissue evaluation of individuals with an ideal occlusion and a well-balanced face." Aesthetics and the treatment of facial form. Monograph 28 (1992): 115-146.

33. Riedel, R.A. The relationship of maxillary structures to cranium in malocclusion and normal occlusion. Angle Orthod. 1952; 22: 142-145.

34. Steiner, CC. Cephalometrics for you and me. Am J Orthod. 1953; 39: 729-755.

35. McNamara JA Jr, Ellis E. Cephalometric analysis of untreated adults with ideal facial and occlusal relationships. Int J Ault Orthodont Oral Surgery 1988; 3: 221-231.

36. Ricketts, RM. The influence of orthodontic treatment on facial growth and development. Angle Orthod. 1960; 30: 103-133.

37. Schudy, FF. Vertical growth versus antero-posterior growth as related to function and treatment. Angle Orthod. 1965; 35: 36-50.

38. Schudy, FF. The rotation of the mandible resulting from growth: Its implications in orthodontic treatment. Angle Orthod. $1965 ; 35: 36-50$.

39. Tollaro I, Baccetti T, Franchi L, et al. Interarch transverse discrepancy in Class II malocclusion during the mixed dentition. Am J Orthod Dentofacial Orthop 1996.

40. Baccetti T, Franchi L, McNamara JA Jr, et al. Early Dentofacial features of Class II malocclusion: A longitudinal study from the deciduous through mixed dentition. Am J Orthod 1973; 63: 610-621.

41. Ayra BS, Savara BS, Thomas DR. Prediction of $1^{\text {st }}$ molar occlusion. Am J Orthod 1973; 63: 610-621.

42. Spillane LM, McNamara JA Jr. Maxillary adaptations following expansion in the mixed dentition. Sem Orthod 1995; 1: 176-187.

43. Wieslander, L. Intensive treatment of severe Class II malocclusion with a HeadgearHerbst appliance in the early mixed dentition. Am J Orthod. 1984; 86: 1-13. 
44. Ruf, S and Pancherz, H. Herbst/multibracket appliance treatment of Class II division I malocclusions in early and late adulthood. A prospective cephalometric study of consecutively treated subjects. Eur J Orthod. 2006; 28: 352-360.

45. Ruf, S, Pancherz, H. Temporomandibular joint remodeling in adolescents and young adults during Herbst treatment: a prospective longitudinal magnetic resonance imaging and cephalometric radiographic investigation. Am J Orthod Dentofacial Orthop 1999; 115: 607-618.

46. Moore, RN. Principles of Dentofacial Orthopedics. Sem Orthod. 1997; 3: 4 212-21.

47. Weinberger, WW. Orthodontics. A historical review of its origin and evolution. Vol. II. The Mosby Company, 1926.

48. Graber, Thomas M., and Bedrich Neumann. Removable orthodontic appliances. WB Saunders Company, 1984.

49. Schwarz, M.: Erfahrungen mit dem Herbstschen Scharnier zur Behandlung des Distalbisses. Zahnärztl. Rundschau, 43: 47-54, 91-100, 1934.

50. Herbst, E.: Dreissigjährige Erfahrungen mit dem Retentionsscharnier. Zahnärztl. Rundschau, 43: 1515-1524, 1563-1568, 1611-1616, 1934.

51. Pancherz H. The Herbst appliance - it's biological effects and clinical use. Am J Orthod. 1985; 87: 1-20.

52. McNamara, JA Jr. Fabrication of the acrylic splint Herbst appliance. Am J Orthod Dentofacial Orthop. 1988; 94: 10-18.

53. Goodman, P, McKenna, P. Modified for the mixed dentition. J Clinc. Ortho. 1985; 19: 811-814.

54. Langford Jr, N. M. (1982). Updating fabrication of the Herbst appliance. Journal of clinical orthodontics: JCO, 16(3), 173-174.

55. Rogers, M. B. (2001). The banded Herbst appliance. Journal of clinical orthodontics: JCO, 35(8), 494.

56. Held, A.J., Spirgi, M., and Cimasoni, G.: An orthopedically treated adult case of Class II malocclusion. Am. J. Orthod. 49: 761-765, 1963.

57. Egermark-Eriksson, I.; Carlsson, G.E., and Ingervall, B. Function and dysfunction of the masticatory system in individuals with dual bite. Eur J. Orthod. 1: 107-117: 1979. 
58. Pancherz H, Hagg U. Dentofacial orthopedics in relation to somatic maduration. An analysis of 70 cases treated with the Herbst appliance. Am J Orthod. 1985; 88: 273-287.

59. Jakobsson SO: Cephalometric evaluation of treatment effect on Class II, Division I malocclusions. Am J Orthod Dentofacial Orthop 53: 446-457, 1967.

60. Baumrind S, Korn EL, Isaacson RJ, et al.: Quantitative analysis of the orthodontic and orthopedic effects of maxillary traction. Am J Orthod Dentofacial Orthop 84: 384-398, 1983.

61. Cozza P, Baccetti, T, Franchi L, Toffol LD, McNamara JA. Mandibular changes produced by functional appliances in Class II malocclusion: A systematic review. Am J Orthod Dentofacial Orthop. 2006; 129: 599.e1-599.e12.

62. Yang EY, Kiyak HA. Orthodontic treatment timing: A survey of orthodontists. Am J Orthod Dentofacial Orthop. 1998; 113: 96-102.

63. Hansen, K., and Pancherz, H. Long-term effects of Herbst treatment in relation to normal growth development: a cephalometric study. Eur. J. Orthod., 14: 285-295, 1992.

64. Pancherz, H., \& Fackel, U. (1990). The skeletofacial growth pattern pre-and postdentofacial orthopaedics. A long-term study of Class II malocclusions treated with the Herbst appliance. The European Journal of Orthodontics, 12(2), 209-218.

65. Hagg U, Pancherz H. Dentofacial orthopedics in relation to chronological age, growth period and skeletal development. An analysis of 72 male patients with Class II division 1 malocclusion treated with the Herbst appliance. Eur. J Orthod. 1988; 10:169-176

66. Pancherz H. The effects, limitations, and long-term dentofacial adaptations to treatment with the Herbst appliance. Sem Ortho. 1997; 3: 232-243.

67. Windmiller EC. The acrylic-splint Herbst appliance. Am J Orthod Dentofacial Orthop. 1993; 104: 73-84.

68. Lai M, McNamara JA Jr. An evaluation of two phase treatment with the Herbst appliance and pre-adjusted edgewise therapy. Sem Ortho 1998; 4: 46-58.

69. Valant JR, Sinclair PM. Treatment effects of the Herbst appliance. Am J Orthod Dentofacial Orthop. 1989; 95: 138-147.

70. Pancherz H. The mechanism of Class II correction in Herbst appliance treatment. A cephalometric investigation. Am J Orthod. 1982a; 82:104-113.

71. McNamara JA Jr, Howe RP, Dischinger TG. A comparison of the Herbst and Frankel appliance in the treatment of Class II malocclusions. Am J Orthod Dentofacial Orthop. 1990; 98: 134-144. 
72. Pancherz H. The effect of continuous bite jumping on the Dentofacial complex: A follow-up study after Herbst appliance treatment of Class II malocclusions. Eur J Orthod. 1981; 3: 49-60.

73. Pancherz H, Littmann C. Somatische Reif undd morphologische Veranderungen des Unterkiefers bei der Herbst-Behandlung. Inf. Orthod. Kieferorthop. 1988; 20: 455-470.

74. Pancherz, H. and Littmann, C. Morphologie und Lage des Unferkiefers bei der HerbstBehandlung. Eine kephalometrische Analyse der Veränderungen bis zum Wachstumsabschluss. Inf. Orthod. Keiferorthop., 21: 493-513, 1989.

75. Chen JY, Will LA, Niederman R. Analysis of the efficacy of functional appliances on mandibular growth. Am J Orthod Dentofacial Orthop 2002; 122: 470-476.

76. Rabie et al. Osteogenesis in the glenoid fossa in response to mandibular advancement. Am J Orthod Dentofacial Orthop. 2001; 119: 390-399.

77. Pancherz H, Hansen K. Occlusal changes during and after Herbst treatment: a cephalometric investigation. . Eur. J Orthod. 1986; 8: 215-228.

78. Pancherz H, Anehus Pancherz M. The head-gear effect of the Herbst appliance. Am J Orthod Dentofacial Orthop. 1993; 103: 510-520.

79. Bjork, A. The face in profile: An anthropological x-ray investigation of Swedish children and Conscripts. Lund: Berlingska Boktrycheriet 1947: 40: 58.0

80. Pancherz, H. Vertical dentofacial changes during Herbst appliance treatment. Swed. Dent. J. Suppl., 15: 189-196, 1982b.

81. VanLaecken R, Martin C, Dischinger T, Razmus T, and Ngan P. Treatment effects of the edgewise Herbst appliance: A cephalometric and tomographic investigation. Am. J. Orthod. Dentofacial Orthop. 2006; 130: 582-591.

82. Wigal, T. G., Dischinger, T., Martin, C., Razmus, T., Gunel, E., \& Ngan, P. (2011). Stability of Class II treatment with an edgewise crowned Herbst appliance in the early mixed dentition: Skeletal and dental changes. American Journal of Orthodontics and Dentofacial Orthopedics, 140(2), 210-223.

83. O'Brien et al. Effectiveness of treatment for Class II malocclusion with the Herbst or Twin-block appliances: A randomized, controlled trial. Am J Orthod Dentofacial Orthop. 2003; 124: 128-137.

84. Du X, Hagg U, Rabie ABM. Effects of headgear Herbst and mandibular step-by-step advancement versus conventional Herbst appliance and maximal jumping of the mandible. . Eur J Orthod. 2002; 24: 167-174. 
85. Konik M, Pancherz H, Hansen K. The mechanism of Class II correction in late Herbst treatment. Am J Orthod Dentofacial Orthop 1997; 112:87-91.

86. Ruf S, Pancherz H. The mechanism of Class II correction during Herbst therapy in relation to the vertical jaw base relationship: a cephalometric roentgenographic study. Angle Orthod 1997; 67: 271-276.

87. Hansen K, Koutsonas TG, Pancherz H. Long-term effects of Herbst treatment on the mandibular incisor segment: a cephalometric and biometric investigation. Am J Orthod Dentofacial Orthop 1997; 112:92-103.

88. Obijou C, Pancherz H. Herbst appliance treatment on Class II, division 2 malocclusions. Am J Orthod Dentofacial Orthop 1997; 112:287-291.

89. Omblus J, Malmgren O, Pancherz H, Hagg U, Hansen K. Long-term effects of Class II correction in Herbst and Bass therapy. Eur J Orthod 1997; 19: 185-193.

90. Franchi L, Baccetti T, McNamara JA Jr. Treatment and post-treatment effects of acrylic splint Herbst appliance therapy. Am J Orthod Dentofacial Orthop 1999; 115:429-438.

91. Nelson B, Hansen K, Hagg U. Class II correction in patients treated with class II elastics and with fixed functional appliances: a comparative study. Am J Orthod Dentofacial Orthop 2000; 118:142-149.

92. Hagg U, Du X, Rabie ABM. Initial and late treatment effects of headgear-Herbst appliance with mandibular step-by-step advancement. Am. J. Orthod. Dentofacial Orthop. 2002; 122: 477-485.

93. Burkhart DR, McNamara JA Jr, Baccetti T. Maxillary molar distalization or mandibular enhancement: a cephalometric comparison of comprehensive orthodontic treatment including the pendulum and Herbst appliances. Am J Orthod Dentofacial Orthop 2003; 123:108-116.

94. Valant JR, Sinclair PM. Treatment effects of the Herbst appliance. Am J Orthod Dentofacial Orthop. 1989; 95: 138-147. 
95. Eberhard H, Hirschfelder U. Treatment of Class II, Division 2 in the late growth period. J Orofac Orthop 1998; 59: 352-361.

96. Hansen K, Pancherz H, Hagg U. Long-term effects of the Herbst appliance in relation to the treatment growth period: a cephalometric study. Eur J Orthod 1991; 13: 471-481.

97. Wieslander L. Long-term effect of treatment with the headgear-Herbst appliance in the early mixed dentition. Stability or relapse? Am J Orthod Dentofacial Orthop 1993; 104:319-329.

98. Pancherz H, Malmgren O, Hagg U, Omblus J, Hansen K. Class II correction in Herbst and Bass therapy. Eur J Orthod 1989; 11: 17-30.

99. Wong GW, So LL, Hagg U. A comparative study of sagittal correction with the Herbst appliance in two different ethnic groups. Eur J Orthod 1997;19: 195-204.

100. Sidhu MS, Kharbanda OP, Sidhu SS. Cephalometric analysis of changes produced by a modified Herbst appliance in the treatment of Class II division 1 malocclusion. Br J Orthod 1995; 22: 1-12.

101. Baltromejus S, Ruf S, Pancherz H. Effective termporomandibular joint growth and chin position changes: activator versus Herbst treatment. A cephalometric roentgenographic study. Eur J Orthod 2002; 24: 627-637.

102. Pancherz H, Fackel U. The skeletofacial growth pattern pre-and post-dentofacial orthopaedics: a long-term study of Class II malocclusions treated with the Herbst appliance. Eur J Orthod. 1990; 12: 209-218.

103. Pancherz H, Hansen K. Mandibular anchorage in Herbst treatment. Eur J Orthod 1988; 10: 149-164.

104. Hansen K, Iemamnueisuk P, Pancherz H. Long-term effects of the Herbst appliance on the dental arches and arch relationships: a biometric study. Br J Orthod 1995; 22: 123-134.

105. Schweitzer M, Pancherz H. The incisor-lip relationship in Herbst/multibracket appliance treatment of Class II, Division 2 malocclusions. Angle Orthod 2001; 71: 358363. 
106. Ruf S, Pancherz H. The effect of Herbst appliance treatment on the mandibular plane angle: a cephalometric roentgenographic study. Am J Orthod Dentofacial Orthop 1996; 110:225-229. 


\title{
IRB APPROVAL
}

\author{
West VirginiaUniversity; \\ Office of Research Integrity and Compliance

\section{Acknowledgement Letter Not Human Subject Research NHSR} \\ To \\ From \\ Action Date \\ Approval Period \\ Subject \\ Protocol Number \\ Title \\ Peter Ngan \\ WVU Office of Research Integrity and Compliance \\ 02/03/2015 \\ 02/03/2015 Expiration Date 02/02/2020 \\ Not Human Subject Research Acknowledgment \\ 1405291690 \\ A Radiographic Study of Patients Treated with the Reinforced Banded Herbst \\ Appliance
}

Thank you for your submission to the West Virginia University Institutional Review Board IRB.

It has been determined that your project does not meet the definition of human subject research for the following reasons:

" In order to be considered human subject research, individually identifiable private information must be obtained or used in the research. If there is no individually identifiable private information involved, the project is not human subject research and does not require being submitted to the Office of Research Integrity \& Compliance. Private information must be individually identifiable (i.e., the identity of the subject is or may be readily ascertained by the investigator or someone else associated with the information) in order to constitute research involving human subjects.

The Office of Research Integrity and Compliance is here to provide assistance to you from the initial submission of an IRB protocol to its approval and all subsequent activity. Please feel free to contact us by phone at 304.293.7073 with any question you may have. Thank you.

WVU Office of Research Integrity and Compliance

Date: $02 / 03 / 2015$

Signed:



Afton Wagner IRB Administrator 